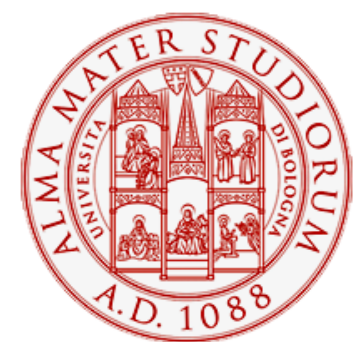

Alma Mater Studiorum - Università di Bologna DEPARTMENT OF ECONOMICS

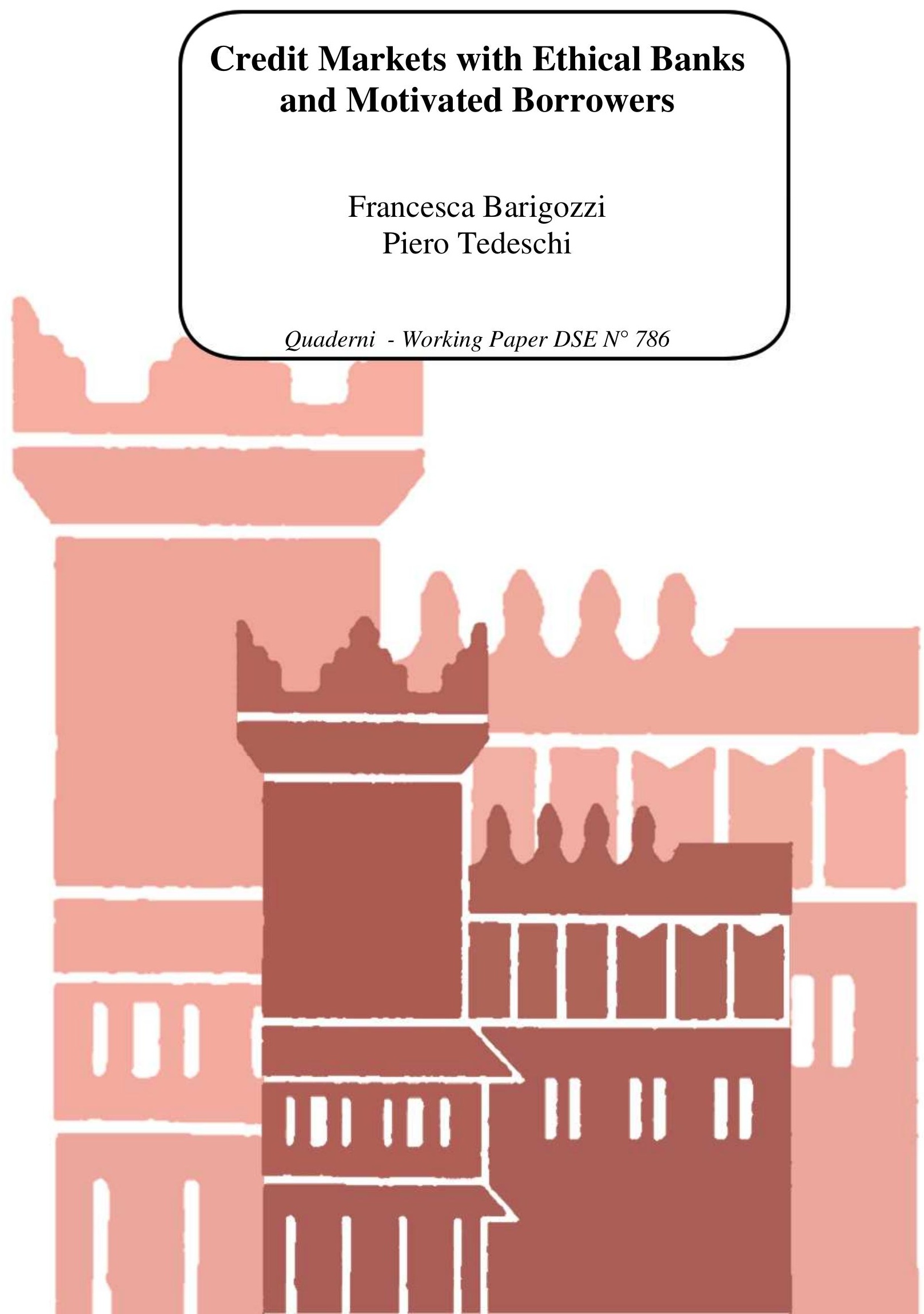




\title{
Credit Markets with Ethical Banks and Motivated Borrowers*
}

\author{
Francesca Barigozzi ${ }^{\dagger}$ \\ University of Bologna
}

\author{
Piero Tedeschi ${ }^{\ddagger}$ \\ Università Cattolica - Milano
}

November 2012

\begin{abstract}
This paper investigates banks' corporate social responsibility. The credit market is composed of two sectors: one for standard and one for ethical projects. Since ethical banks are committed to investing in ethical projects, standard and ethical banks compete in the market for ethical projects. The latter have also a social profitability, but a lower expected revenue with respect to standard ones. If their expected revenue is not too low, ethical projects are undertaken by motivated borrowers. The latter obtain a benefit (a social responsibility premium) from accomplishing ethical projects in general and a premium for successful interaction when trading with ethical banks in the case the project is successful.

If the expected profitability of ethical projects is sufficiently close to that of standard ones and/or the premium for successful interaction of motivated borrowers is sufficiently high, ethical banks are active, both sectors of the credit market exist and the whole market is fully segmented. This result holds true irrespective of the information structure: only moral hazard on the borrower side, moral hazard and screening on the borrower side. The optimal contract in our set-up is always a debt contract. However, its precise form and welfare properties depend on the information structure.

Jel classification: D86, G21, G30.

Key-words: corporate social responsibility, ethical banks, motivated borrowers.

\footnotetext{
${ }^{*}$ We are indebted to Mohamed Belhaj, Alberto Bennardo, Giacomo Calzolari, Gabriella Chiesa, Davide Dragone, Nataliya Klimenko, Antonio Nicolò, Salvatore Piccolo and Giuseppe Pignataro for helpful comments and suggestions. We are also grateful to the audience at seminars of the University of Bologna, Padua, Naples. The paper was also presented at the 10th edition of the Journées d'Economie Publique Louis-André Gérard-Varet in Marseille and at the 27th Annual Congress of the European Economic Association in Malaga.

${ }^{\dagger}$ Department of Economics, University of Bologna and CHILD, P.zza Scaravilli 2, 40126 Bologna (Italy). E-mail: francesca.barigozzi@unibo.it

¥Istituto di Economia dell'Impresa e del Lavoro Università Cattolica del Sacro Cuore di Milano. E-mail: piero.tedeschi@unicatt.it
} 


\section{Introduction}

According to the standard shareholder-value approach firms are controlled by profit-maximizing shareholders and the firms' interaction with other stakeholders is simply managed by contracts and regulation. However, in recent years, society's and lawmakers' interest and demand for corporate social responsibility (CSR) have dramatically increased: the recently updated OECD Guidelines for Multinational Enterprises, and the United Nations Guiding Principles on Business and Human Rights are internationally recognized principles. The Green Paper "Promoting a European framework for Corporate Social Responsibility" was prepared by the Commission of the European Communities in 2001 and the new document "A renewed EU strategy for Corporate Social Responsibility" was published in 2011. CSR has been interpreted as a response to market and redistributive failures alternative to government intervention. Following Benabou and Tirole (2009), "a standard definition of CSR is that it is about sacrificing profits in the social interest. For there to be a sacrifice, the firm must go beyond its legal and contractual obligations, on a voluntary basis. CSR embraces a wide range of behaviors, such as being employee friendly, environment friendly, mindful of ethics, respectful of communities where the firm's plants are located, and even investor friendly" (Bénabou and Tirole 2009, page 2). In practice, as the authors clarify, CSR can be translated essentially in one of the three following situations: the adoption of a more long-term perspective by firms, the delegated exercise of prosocial behavior on behalf to stakeholders, and insider-initiated corporate philanthropy.

CSR is also developing in the banking industry and it is becoming an important tool for many companies' management and work force. CSR by lenders (Ethical Banks) can be interpreted as delegated philanthropy since, as mentioned before, the firm can be a channel of stakeholders' values. In the case of banking, investors are obviously crucial stakeholders: socially responsible investors provide savings to ethical banks and want the corporation to use their saving to finance social responsible project and firms ${ }^{1}$ (see, for example, the Report on Socially Responsible Investing Trends in the U.S. prepared in 2007 by the Social Investment Forum). Example of ethical banks are the following: Wainwright Bank ${ }^{2}$ and ShoreBank ${ }^{3}$ in the U.S.A., Cooperative Bank and Charity Bank in the U.K., Ekobank in Sweden, Cultura Sparebank in Norway, Trio-

\footnotetext{
${ }^{1}$ Socially responsible investors frequently accept, for their investment, a lower interest rate with respect to the market one.

${ }^{2}$ Eastern Bank Corp. has agreed to buy Wainwright Bank \& Trust Co. in 2010. Since its founding in 1987, Wainwright's mission has been to invest in "socially responsible development projects," including ones related to the environment, affordable housing, AIDS, homeless shelters, and immigration. (See "Eastern Bank to buy Wainwright" - The Boston Globe, June 30, 2010)

${ }^{3}$ ShoreBank was founded in 1973 to prove that money could be lent profitably to poor people in poor neighborhoods, an experiment that became known as "communitydevelopment finance". On August 2010 the Federal Deposit Insurance Corporation (FDIC), called time on its experiment. (From "ShoreBank: Small Enough to Fail - The Sorry End to a Bold Banking Experiment". Economist. August 26, 2010, available at http://www.economist.com/node/16891993).
} 
dos Bank in the Netherlands, Ethikbank and GLS Bank in Germany, LaNef in France, Banca Popolare Etica and Banca Prossima in Italy, Grameen Bank in Bangladesh, BID Amerique in Latin America and in the Caribbean area. In Islamic banking (spread over 51 countries, including the United States), interestfree loan (qard hassan) are today quite frequent and funds must comply with Islamic principles (see also the Islamic Development Bank).

Also borrowers, when accomplishing ethical projects, can promote social values. Motivated borrowers may invest in projects providing services to individuals (for example services to persons with disabilities or rehabilitation services), culture and education diffusion, may invest in projects promoting the environment as well as art fruition and protection, access to work, protection and enhancement of minorities, local and community development and so forth.

We define ethical banks as "corporate social responsible" lenders since they can commit to fund only socially relevant projects. While borrowers are called "motivated" since they prefer to engage in socially valuable activities, without necessarily committing to them.

In spite of its importance, little consideration is given in the economics literature to ethics in finance in general and to ethics in banking in particular (exception is the literature on microcredit, e.g., Stiglitz 1990, Besley and Coate 1995, Ghatak 1999 and the large empirical literature which followed). Few works, mainly in the business literature, analyze ethical banks and show the relevant role of ethical banking as an independent activity (e.g., Lynch, 1991; San-Jose, Retolaza and Gutierrez, 2009). From Green (1989) and Lynch (1991) there are two accepted characteristics to define the ethical banking: i) social profitability, understood as funding economic activities with social added value and as the absence in any case of investments in speculative projects or in those that fulfill negative social criteria; ii) economic profitability, which means non negative profits. The dimension of profit obviously refers to bank good management, because ethical banks distribute benefits amongst stockholders only to a limited extent.

In this paper we analyze banks CSR when offering loan agreements to entrepreneurs wishing to invest in ethical projects. In particular we investigate how social responsible lenders and motivated borrowers interact with each other when they compete in a credit market where also standard lenders and standard borrowers do operate.

In the model, ethical projects are those providing both social ${ }^{4}$ and economic advantages, but which deliver lower expected revenue with respect to standard ones. Different from standard profit maximizing banks, socially responsible

\footnotetext{
${ }^{4}$ To give some examples of ethical projects, the Co-operative Bank (UK) supports both smaller local charities and high profile international organizations. It invests in projects within the renewable energy and carbon reduction sectors by funding a wide range of renewable energy projects. It provides services to Housing Associations including term loans and investments. It actively supports social enterprises by helping organizations that share its co-operative values of fairness and social responsibility and are committed to transforming lives through making social, economic and environmental change. (From the website http://www.co-operativebank.co.uk, consulted in November 2011)
} 
lenders commit to investing in ethical projects. ${ }^{5}$

Two types of borrowers exist in the market: standard profit maximizing entrepreneurs and socially motivated ones. The latter obtain a non-monetary premium for social responsibility when they can undertake an ethical project. This premium is higher if the project is financed by an ethical bank and the project is successful. We call this additional premium "premium for successful interaction". Given our assumptions, in equilibrium, motivated borrowers prefer to trade with ethical banks as long as loan conditions are not too unfavorable with respect to those offered by standard lenders. Standard borrowers, instead, always prefer to invest in standard projects with standard banks.

Both project types are subject to moral hazard: motivated and standard entrepreneurs can behave or misbehave (see Tirole 2006). As mentioned before, motivated borrowers trading with ethical banks gain the premium for successful interaction when the project is successful, thus making the moral hazard problem less severe. Consequently, if the premium for successful interaction is high enough (and/or the profitability of ethical projects is not much lower than that of standard ones), we show that ethical banks can offer a better contract to motivated borrowers than those offered by standard banks.

First we analyze the case where the borrowers' behavior is private information (moral hazard only). We then investigate the case where the borrowers' behavior and their preferences for social issues are private information (moral hazard and adverse selection both on the borrowers' side).

Our results are all driven by the interplay of the two crucial parameters of the model: the difference in expected revenue from standard and ethical projects and the premium for successful interaction received by motivated borrowers trading with ethical banks in the case the project succeeds.

We first show that only socially motivated borrowers potentially engage in ethical projects. If they do not, then ethical banks cannot operate and the market for ethical projects does not exist. If, instead, motivated borrowers undertake ethical projects, then ethical banks are active and the market is fully segmented. That is, standard agents trade among themselves in the market for standard projects while ethical banks trade with motivated borrowers in the market for ethical projects. This occurs, whatever the information structure considered, when the premium for successful interaction is high enough (and/or the difference between the two projects' profitability is not too large). For larger values of the successful interaction premium, ethical banks are active and they even provide a higher funding to motivated borrowers than what received by standard ones from standard banks, in any considered information structure. Finally, in second-best when the premium further increases, ethical banks guarantee a larger revenue to motivated borrowers than what standard borrowers can obtain. For these parameter values and if the borrowers' type is not ob-

\footnotetext{
${ }^{5}$ As an example of commitment to ethical projects, on the web site of Charity Bank (UK) one reads "Providing affordable charity loans and loans to social enterprises and other community organizations that benefit people and the planet, is our mission. As a charity and social enterprise ourselves we understand how the sector works and are here to help your organization". (Available at http://www.charitybank.org, consulted in November 2011)
} 
servable, standard borrowers would like to mimic motivated ones in order to obtain the better contract conditions. As a consequence, in third-best, for high values of the premium for successful interaction, self selection requires that motivated borrowers are worse off with respect to the second-best, while standard borrowers receive the second best contract. Finally, whatever the information structure considered, the optimal contract is always a debt one in both credit markets.

In short, perfect segmentation of the credit market always increases the overall efficiency. When the premium for successful interaction is high enough (and/or the differential between profitability of the two project types is sufficiently low), increased efficiency is driven by the overall premium for social responsibility that increases the welfare of motivated borrowers undertaking ethical projects beyond the simple expected profit. If the premium for successful interaction is even larger, then there is a further efficiency gain, since the socially responsible lenders and the motivated borrowers solve the moral hazard problem in a cheaper way if they are matched together than if they are matched with standard agents.

Our paper shares some similarities with Besley and Ghatack (2007) who interpret CSR as the private provision of a public good in the product market. In particular, the idea of motivated and standard borrowers operating in the credit market is close to that of "caring" and "neutral" consumers coexisting in the product market, where caring consumers are those who evaluate the public good. Moreover, borrowers self-selecting either in the market for ethical projects or in that for standard ones recall consumers choosing, in equilibrium, either ethical brands or neutral ones. In both papers, CSR of banks in the credit market and of firms in the product market is interpreted as a form of "delegated philanthropy" and, competition leads banks' and firms' profits to zero at the equilibrium. However, an important difference with respect to Besley and Ghatack (2007) is that they solve a model with full information, whereas we consider asymmetric information, which is a crucial issue in the credit market.

Finally, the beneficial matching between agents of similar type recalls Besley and Ghatack (2005). However, they assume that the workers' and employers' types (whether the worker is mission oriented or not) are observable by the partner; we instead consider also the case where private information exists on the borrowers' type as well. As a consequence the first part of our paper investigates a situation similar to the one analyzed by Besley and Ghatack (2005) and referring to a two sectors market, while the second one considers an extension to the case of asymmetric information on the borrowers' type.

Our paper is organized as follows. In Section 2 we describe how socially responsible lenders and motivated borrowers are modeled and how they interact in the market where also standard profit maximizer agents exist. We also present the different information structures considered in the paper. In Section 3 we investigate loan agreements when the motivated and standard borrowers have private information on the behavior exerted in making the project successful. In Section 4 we analyze the case of loan agreements under moral-hazard and adverse selection on the borrowers' side. Finally, Section 5 concludes. 


\section{The Model Set-up}

The model borrows from Tirole (2006). We consider a credit market with a large number of both risk neutral borrowers (she) and banks (it). We assume zero risk free interest rate and an infinitely elastic supply of funds in the deposit market.

Borrowers have to undertake a project which needs an investment. Each borrower can apply for at most one loan and different projects type exist. We call $I^{k}$ the amount of the investment, where $k \in\{0,1\}$ is an indicator of the type of project. When $k=1$ the project is "ethical" and when $k=0$ the project is "not-ethical" or standard. The difference between the two projects will be specified below. The borrower owns an asset $A$, with $A<I^{k}$. In words, the borrowers have not enough capital and/or collateral whichever project they are interested in, hence they have to borrow $I^{k}-A$. We assume for simplicity that $A$ is the same for all borrowers. ${ }^{6}$

If the project is undertaken it generates a cash flow per unit of investment $R^{k} \in\left\{R^{F k}, R^{S k}\right\}$, with $R^{S k}>R^{F k} \geq 0$, where $R^{S k}$ is the cash flow per unit of investment in case of success, and $R^{F k}$ in case of failure.

Ethical projects represent all projects leading to social benefits, beyond profits (as an example projects that improve communities, and have a positive impact on the environment). We do not model this aspect of ethical projects, which will then be taken for granted. Ethical projects can be thought of as being a subset of standard ones. For this reason one can assume that the profitability of ethical projects is on average lower than that of standard ones. We capture this idea by assuming that standard projects have a higher return in case of success, that is: $R^{S 0} \geq R^{S 1}$ and $R^{F 0}=R^{F 1}=R^{F}$, such that $\Delta_{R_{0}}=R^{S 0}-R^{F}$ $>\Delta_{R_{1}}=R^{S 1}-R^{F}$. The two types of projects are perfectly observable and have independent distributions. Finally, and considering both projects types, the total cash flow is $R^{X k} \cdot I^{k}>0$, with $X \in\{F, S\} . R^{F} I^{k}$ can be considered as the liquidation value of the assets.

To summarize, in the credit market two sectors exist: the market for ethical projects and the market for standard ones. The latter assures higher expected returns to investors.

The project is subject to moral hazard: the entrepreneurs can behave or misbehave. If they behave the probability of success is $p_{H}$, otherwise it is $p_{L}$, with $p_{H}>p_{L}$. We define $\Delta_{p} \equiv p_{H}-p_{L}$. An entrepreneur who misbehaves will enjoy a private benefit whose value is $P \cdot I$. The private benefit will be nought otherwise. The borrowers are protected by limited liability: hence their income cannot be negative. Given limited liability, the moral hazard problem is relevant even though both agents are risk neutral.

There are also two types of banks and entrepreneurs, denoted respectively as $i \in\{0,1\}$ and $j \in\{0,1\}$. Both for lenders and borrowers type 0 denotes the standard profit maximizing agents, while type 1 indicates the agents aware of

\footnotetext{
${ }^{6}$ See Section 5 for a short discussion on the implications of the alternative assumption that ethical projects require a lower collateral $A$ than standard ones.
} 
social issues. The percentage of motivated borrowers in the credit market is $q$ whereas that of standard ones is $1-q$. This information is common knowledge.

Both in case of success and of failure, revenues are shared between lenders and borrowers: $L_{i j}^{X k}$ and $B_{i j}^{X k}$ are respectively the income of a lender of type $i$ and that of a borrower of type $j$ when trading with each other, if the investment is of type $k$ and the state of the world is $X$. We obviously have that $L_{i j}^{X k}+B_{i j}^{X k}=$ $R^{X k} \cdot I_{i j}^{k}$. Thus, a contract $\left(B_{i j}^{S k}, B_{i j}^{F k}, I_{i j}^{k}\right)$ specifies the type of project, the amount invested and, how revenues are shared between lenders and borrowers both in case of success and of failure, given the type of the two agents trading together.

The entrepreneurs payoff is:

$$
U_{j}^{k}=p(a)\left(B_{i j}^{S k}+\theta_{i j}^{S k}\right)+(1-p(a))\left(B_{i j}^{F k}+\theta_{i j}^{F k}\right)-A+(1-a) P I_{i j}^{k}
$$

where $a \in\{0,1\}$ is the behavior of the entrepreneur. In particular, $a=0$ if the entrepreneur misbehaves, while $a=1$ if she behaves. The entrepreneur's behavior determines the probability of success which becomes $p(1)=p_{H}$ and $p(0)=p_{L}$ respectively.

Motivated borrowers can receive a premium for social responsibility, a non pecuniary benefit with monetary value $\theta_{i j}^{X k}$. Or, in line with Besley and Ghatack (2007)'s interpretation of ethical and neutral consumers, motivated borrowers "care" for the social benefit produced by ethical projects, whereas standard borrowers do not.

Thus, the premium depends on the type of project and on the type of lender in the following way:

$$
\begin{aligned}
& \theta_{i j}^{X 0}=0, \forall X \in\{F, S\} \\
& \theta_{01}^{X 1}=\theta, \forall X \in\{F, S\} \\
& \theta_{11}^{S 1}=\theta^{S}>\theta_{11}^{F 1}=\theta
\end{aligned}
$$

In words, the premium for social responsibility is positive only if a motivated borrower undertakes an ethical project. In particular, $\theta_{01}^{X 1}=\theta$ is the premium when a motivated borrower undertakes an ethical project interacting with a standard bank, whatever the project's outcome. Whereas, when the motivated borrower contracts with an ethical bank, the premium is higher in the case of success than in the case of failure: $\theta_{11}^{S 1}=\theta^{S}>\theta_{11}^{F 1}=\theta$. This occurs since, in a dynamic perspective, the motivated borrower anticipates that, if the ethical bank makes profits, it will use the liquidity to finance other social and solidaritybased projects. We define $\Delta_{\theta}=\theta^{S}-\theta$, the premium for successful interaction, that is, the additional premium of social responsibility accrued to a motivated agent when she accomplishes an ethical project which was financed by an ethical bank. ${ }^{7}$

\footnotetext{
${ }^{7}$ As it will be probably clear after we presented our main propositions, our results are robust to the generalization $\theta_{01}^{S 1}>\theta_{01}^{F 1}=\theta_{11}^{F 1}$, provided that $\theta_{11}^{S 1}>\theta_{01}^{S 1}$. In words: the motivated borrower also receives an additional premium for successful interaction when she
} 
In practice, the motivated borrower always obtains the premium when undertaking an ethical project but, once the loan contract has been signed, she has more willingness to repay the debt to a socially responsible lender. Our assumption is in line with Besley and Ghatack's idea of good matching between agents sharing the same mission.

Note that motivated borrowers prefer to undertake ethical projects as long as their profitability is not too low with respect to standard ones. In that case the total premium for social responsibility $\theta+\Delta_{\theta}$ can eventually compensate the difference in profitability between the two project types, as we will show below. In our formulation, the motivated borrower behaves as a standard one, if the gains in profits are sufficiently high. This is in line with the behavioral literature where it is acknowledged that the psychological motives are relevant if the material payoffs are not too big (see Rabin 1993).

On the contrary standard borrowers prefer the loan the contract that assures them the highest expected revenue, whatever the type of project involved.

As we will show in Subsection 3.2, when the premium for successful interaction is sufficiently high and ethical projects profitability is not too low, ethical banks can control moral hazard at a lower cost with respect to standard lenders trading with borrowers of the same type.

Standard lenders maximize their profits. When moral hazard problem is taken care of, their expected profits become:

$$
p_{H} L_{0 j}^{S k}+\left(1-p_{H}\right) L_{0 j}^{F k}-I_{0 j}^{k}+A
$$

In principle, standard lenders can invest both in ethical and in standard projects. In equilibrium, however, we will show that standard banks invest only in standard projects. In fact, standard borrowers prefer to undertake standard projects given the latter's higher expected revenue. Moreover, when undertaking ethical projects, and all else equal, motivated borrowers prefer to trade with ethical banks because of the premium for successful interaction $\Delta_{\theta}$.

As mentioned in the introduction we interpret lenders' corporate social responsibility as delegated philanthropy. In particular, the bank is a channel of its stakeholders values: socially responsible investors provide savings to ethical banks and want the corporation to use their saving to finance social responsible projects. In particular, ethical banks maximize expected profit as standard lenders but, differently from them, commit in investing only in ethical projects. ${ }^{8}$

trades with a standard lender, provided that such a premium is lower than the one she receives when successfully trading with an ethical bank.

This assumption would capture an additional premium for the success of the ethical project, whatever the bank financing it. The crucial assumption is that the premium for successful interaction depends on the type of lender in such a way that $\theta_{11}^{S 1}>\theta_{01}^{S 1}$. In fact, a successful ethical project financed by an ethical bank necessarily implies that new ethical projects will be financed in the future, whereas a successful ethical project financed by a standard bank does not.

${ }^{8}$ In a previous version of the paper we assumed that ethical banks maximized the total revenue from ethical projects, in analogy with Blinder (1993)'s assumption for stakeholderoriented manufacturing firms. Nothing substantial changed in the analysis with respect to the current version. 
As a consequence, socially responsible lenders' objective function is:

$$
p_{H} L_{1 j}^{S 1}+\left(1-p_{H}\right) L_{1 j}^{F 1}-I_{1 j}^{1}+A
$$

Note that ethical banks only invest in ethical projects, no matter which type of borrower is undertaking the ethical project, so that we can set $k=1$ in (3). Since ethical projects have a lower profitability than standard ones, ethical banks are ready to sacrifice profits for the social interest. This is in line with the definition of CSR provided in the introduction.

\subsection{Information Structures}

The assumption that the ethical nature of the project is common knowledge seems rather natural, in fact it implies that the creditor can observe the investment that was financed. ${ }^{9}$

We will consider two versions of the model. In both versions the project type is common knowledge and borrowers have private information on their behavior (which may or may not increase the probability of success of the project).

In the former version of the model, the banks observe whether the borrowers are motivated or not, but lenders cannot observe the borrowers' behavior. Hence, we do not allow for adverse selection issues. We call this model the second-best one (Section 3).

Thereafter we relax the assumption that the agents' types are common knowledge and we capture the situation called "strategic corporate social responsibility" (see Baron 2001) where a firm can pretend to be socially responsible only to strengthen its market position. In our setting, standard borrowers are interested in receiving the contract designed for motivated borrowers since, under some conditions, such a contract is preferred to the one designed for standard borrowers. The case of moral hazard and adverse selection on the borrowers' side refers to the empirically relevant situation where lenders are banks that built up a reputation or can set up credible commitment devices in their statute, while borrowers are start-ups, new firms without reputation. We call the solution of this model third-best and we characterize the optimal contracts in Section $4 .{ }^{10}$

\subsection{Preliminaries}

Let us consider the cash flow per unit of investment $I$. In this subsection we omit the superscript of the project type, $k$, since this does not raise any confusion.

\footnotetext{
${ }^{9}$ However, the borrower could use the loan to finance projects different from the contracted one. In the present model, we will not deal with this kind of moral hazard and leave it for future research.

${ }^{10}$ In a previous version of the model, we also considered the situation where standard banks may desire to attract motivated borrowers by pretending to be socially responsible. This has meaning when lenders cannot observe the borrowers' behavior but have private information on their own corporate social responsibility. Such a case turns out to be quite trivial because of the zero profit condition for lenders implying that the second-best allocation is always implemented.
} 
We will assume:

$$
\begin{aligned}
p_{H} R^{S} I_{i j}+\left(1-p_{H}\right) R^{F} I_{i j}-I_{i j} & >0 \\
p_{L} R^{S} I_{i j}+\left(1-p_{L}\right) R^{F} I_{i j}+P I_{i j}-I_{i j} & <0
\end{aligned}
$$

therefore the net present value of both projects (ethical and non-ethical) is positive if the borrower behaves and negative otherwise. The two conditions can be simplified into:

$$
\begin{aligned}
p_{H} \Delta_{R}+R^{F} & >1 \\
p_{L} \Delta_{R}+R^{F}+P & <1
\end{aligned}
$$

Hence, if it is not possible to take care of the moral hazard problem the investment, in both standard and ethical projects, cannot be carried over.

Expected profit of both standard and socially responsible lenders must be non negative. The two lenders' participation constraints $\left(I R_{0 j}^{L}\right)$ and $\left(I R_{1 j}^{L}\right)$, thus, correspond to:

$$
p_{H} L_{i j}^{S}+\left(1-p_{H}\right) L_{i j}^{F} \geq I_{i j}-A .
$$

that is:

$$
\begin{aligned}
p_{H}\left(R^{S} I_{i j}-B_{i j}^{S}\right)+\left(1-p_{H}\right)\left(R^{F} I_{i j}-B_{i j}^{F}\right) & = \\
p_{H}\left(R^{S}-R^{F}\right) I_{i j}-p_{H}\left(B_{i j}^{S}-B_{i j}^{F}\right)+R^{F} I_{i j}-B_{i j}^{F} & \geq I_{i j}-A
\end{aligned}
$$

or

$$
p_{H} \Delta_{R} I_{i j}+R^{F} I_{i j}-I_{i j}-B_{i j}^{F}+A \geq p_{H} \Delta_{B_{i j}}
$$

where $\Delta_{B_{i j}}=B_{i j}^{S}-B_{i j}^{F}$.

\section{Loan Agreements under Moral Hazard}

Corporate social responsibility of both borrowers and lenders is observable, but lenders cannot observe the borrowers' behavior.

Remember that motivated borrowers will undertake ethical projects and eventually trade with ethical banks as long as the expected profit from ethical projects is not too low with respect to the expected profit from standard ones. Moreover, ethical banks will finance only ethical projects, in principle, to both kinds of investor. Instead, commercial banks will potentially finance both kind of projects.

In this section we will characterize the market structure showing which type of lender is active in which sector and find conditions for full segmentation. To do so we will derive optimal contracts that obviously depend on the sector considered and on the types of the agents trading together.

We assume Bertrand competition among lenders so that banks' profits are zero at the equilibrium and borrowers consequently keep all the surplus from 
loan agreements. In the moral hazard setting, this is equivalent to endowing the borrowers with all the bargaining power and having them propose the contract to lenders. Following this interpretation, lenders can accept or refuse the borrower's proposal. Subsequently, the borrower decides whether to behave or to misbehave and, finally, uncertainty concerning the project is solved and the contract is implemented. Finally, the optimal contract maximizes the representative borrower's utility under the borrower's incentive compatibility constraint $\left(I C_{i j}^{B k}\right)$ and the lenders' participation constraint $\left(I R_{i j}^{L k}\right)$.

To characterize the credit market structure under pure moral hazard we first derive all optimal contracts possibly signed by standard borrowers in Section 3.1 ; then all optimal contracts possibly signed by motivated ones in Section 3.2. Finally in Section 3.3, for both borrowers' types we identify the preferred contract and we find out the equilibrium arising in the market for standard projects and in the one for ethical projects respectively.

More in details, we proceed in the following way: (i) in Subsection 3.1.1, we find out the optimal contract signed by standard borrowers when contracting standard projects with standard lenders. (ii) In Subsection 3.1.2, we characterize the optimal contract signed by standard borrowers when investing in ethical projects (which is the same whatever the type of the bank) and we conclude that standard borrowers always prefer to undertake standard projects (with standard lenders). (iii) We observe that motivated borrowers, when they invest in standard projects with standard banks, receive the very same contract as standard borrowers do (see Subsection 3.2.1). (iv) We characterize the contract signed by motivated borrowers when investing in ethical projects with standard lenders and with ethical banks respectively, and we observe that the latter contract is necessarily dominating the former one (see Subsection 3.2.2).

From the previously described facts we just learn the following: standard borrowers always sign a contract with a standard bank for a standard project, whereas motivated borrowers can either sign the very same contract or they can invest in an ethical project with an ethical bank. Thus, the market structure arising at the equilibrium depends on the motivated borrowers' choice between investing in a standard project with a standard bank or in an ethical one with an ethical bank. (v) To find out the motivated borrowers' preferred choice we compare their profits under the two previous contracts and we show that motivated borrowers are willing to trade with ethical banks only when the premium for successful interaction is sufficiently high (and/or the difference in profitability between the two projects types is sufficiently low). This allows us to identify conditions such that the market for ethical projects exists and thus ethical banks can operate.

\subsection{Standard Borrowers}

We now describe optimal contracts for standard borrowers when they invest in standard and in ethical projects respectively. 


\subsubsection{Standard borrowers undertaking standard projects}

When borrowers undertake a standard project, they will trade with a standard bank. The contract is denoted by $\left(B_{00}^{S 0}, B_{00}^{F 0}, I_{00}^{0}\right)$. We recall that the subscript 00 denotes a contract between standard borrowers and standard banks and the superscript 0 means that the borrowers invest in standard projects. The incentive compatibility constraint of borrowers is $\left(I C_{00}^{B 0}\right)$ :

$$
p_{H} \cdot B_{00}^{S 0}+\left(1-p_{H}\right) B_{00}^{F 0}-A \geq p_{L} \cdot B_{00}^{S 0}+\left(1-p_{L}\right) B_{00}^{F 0}+P \cdot I_{00}^{0}-A
$$

that is:

$$
\Delta_{B_{00}^{0}} \geq \frac{P I_{00}^{0}}{\Delta_{p}}
$$

where $\Delta_{B_{00}^{0}}=B_{00}^{S 0}-B_{00}^{F 0}$, which is the difference in the borrower's revenue in case of success and failure, for given contract.

Following Tirole (2006), chapter 3, the problem of a borrower contracting a loan for a standard project with a standard lender becomes:

$$
\begin{array}{ccc}
\max _{\Delta_{B_{00}^{0}}, B_{00}^{F 0}, I_{00}^{0}} & p_{H} \Delta_{B_{00}^{0}}+B_{00}^{F 0}-A & \\
\text { s.t. } & \Delta_{B_{00}^{0}} \geq \frac{P I_{00}^{0}}{\Delta_{p}} & \left(I C_{00}^{B 0}\right) \\
& \left(p_{H} \Delta_{R_{0}}+R^{F}-1\right) I_{00}^{0}-p_{H} \Delta_{B_{00}^{0}} & \left(I R_{00}^{L 0}\right) \\
& -B_{00}^{F 0}+A \geq 0 &
\end{array}
$$

where the participation constraint for standard lenders $\left(I R_{00}^{L 0}\right)$ has been obtained from inequality $(7) .{ }^{11}$

In Subsection 3.2.1 we will observe that the contract $\left(B_{00}^{S 0 *}, B_{00}^{F 0 *}, I_{00}^{0 *}\right)$ is also offered to motivated borrowers trading with standard banks and we will prove that it is a debt contract. Thus, we refer the reader to Subsection 3.2.1 for the characterization of the contract solving Program (9) and its economic interpretation.

\subsubsection{Standard borrowers undertaking ethical projects}

The standard borrower can undertake an ethical project either with an ethical or with a standard bank. In the two cases the problem to be solved is identical and the contract is denoted by $\left(B_{i 0}^{S 1}, B_{i 0}^{F 1}, I_{i 0}^{1}\right)$, where the subscript $i 0$ means

${ }^{11}$ Moreover, always following Tirole (2006), we assume that:

$$
p_{H}\left(\Delta_{R_{0}}-\frac{P}{\Delta_{p}}\right)+R^{F}<1
$$

therefore $I_{00}^{0}$ has to be finite:

$$
I_{0 j}^{0} \leq \frac{A-B_{0 j}^{F 0}}{1-p_{H}\left(\Delta_{R_{0}}-\frac{P}{\Delta_{p}}\right)-R^{F}}
$$

the previous inequality expresses the borrowing capacity of the entrepreneur, contracting with a profit maximizing lender in the case of a standard project. 
that we are considering standard borrowers indifferently trading with either a standard or an ethical bank and the superscript 1 means that the borrowers invest in ethical projects.

The program here is identical to (9), except for the fact that the expected revenue of the ethical project is lower than that of the standard one $\left(\Delta_{R_{1}}<\Delta_{R_{0}}\right) .{ }^{12}$ Thus, we can easily prove that the optimal contract for a standard borrower undertaking an ethical project is a debt contract with the same structure than the contract solving (9) but lower expected revenue in the case of success, $B_{i 0}^{S 1 *}<B_{00}^{S 0 *}$, and lower borrowing capacity, $I_{i 0}^{1 *}<I_{00}^{0 *}$.

The standard borrower obviously makes higher profits with a standard project than with an ethical one and therefore will always prefer the former to the latter. This implies that standard borrowers will always perform standard projects financed by standard lenders.

Lemma 1 Standard borrowers under pure moral hazard:

- when undertaking an ethical project, standard borrowers are indifferent between contracting with a standard bank and contracting with an ethical one since they receive the same contract $\left(B_{i 0}^{S 1 *}, B_{i 0}^{F 1 *}, I_{i 0}^{1 *}\right)$.

- Standard borrowers always prefer to undertake standard projects with standard banks. At the second-best equilibrium they will therefore sign the contract $\left(B_{00}^{S 0 *}, B_{00}^{F 0 *}, I_{00}^{0 *}\right)$ characterized in (12) below.

We now are going to describe all optimal contracts potentially signed by motivated borrowers.

\subsection{Motivated Borrowers}

We just saw that two different contracts are potentially available to standard borrowers: the one signed in the case of standard projects $\left(B_{00}^{S 0 *}, B_{00}^{F 0 *}, I_{00}^{0 *}\right)$ and the one in the case of ethical projects $\left(B_{i 0}^{S 1 *}, B_{i 0}^{F 1 *}, I_{i 0}^{1 *}\right)$, where the latter is independent of the type of the bank. Motivated borrowers, instead, can potentially sign three different contracts: two contracts with standard lenders, in the case of standard $\left(B_{01}^{S 0 *}, B_{01}^{F 0 *}, I_{01}^{0 *}\right)$ and ethical projects $\left(B_{01}^{S 1 *}, B_{01}^{F 1 *}, I_{01}^{1 *}\right)$ respectively, and a contract with ethical banks $\left(B_{11}^{S 1 *}, B_{11}^{F 1 *}, I_{11}^{1 *}\right)$. Importantly, we will show that motivated borrowers undertaking ethical projects receive a different contract when trading with standard banks and when trading with ethical ones: $\left(B_{01}^{S 1 *}, B_{01}^{F 1 *}, I_{01}^{1 *}\right) \neq\left(B_{11}^{S 1 *}, B_{11}^{F 1 *}, I_{11}^{1 *}\right)$. This depends on the additional premium for successful interactions that arises when agents aware of social issues trade together.

\footnotetext{
${ }^{12}$ To derive the optimal contract we assume that inequalities (10) and (11) holds for ethical projects as well.
} 


\subsubsection{Motivated borrowers undertaking standard projects}

Remember that, when investing in standard projects, motivated borrowers are equivalent to standard ones. This implies that motivated borrowers undertaking standard projects with standard banks receive the same contract as standard borrowers, that is the contract derived by Program (9) in Subsection 3.1.1. Thus, $\left(B_{01}^{S 0 *}, B_{01}^{F 0 *}, I_{01}^{0 *}\right)=\left(B_{00}^{S 0 *}, B_{00}^{F 0 *}, I_{00}^{0 *}\right)=\left(B_{0 j}^{S 0 *}, B_{0 j}^{F 0 *}, I_{0 j}^{0 *}\right)$, where the subscript $0 j$ means that we are considering standard lenders indifferently trading with either a standard or a motivated borrower.

Lemma 2 The optimal contract for both motivated and standard borrowers undertaking a standard project financed by a standard lender under moral-hazard is the debt contract $\left(B_{0 j}^{S 0 *}, B_{0 j}^{F 0 *}, I_{0 j}^{0 *}\right)$ such that:

$$
\begin{aligned}
I_{0 j}^{0 *} & =\frac{A}{1-p_{H}\left(\Delta_{R_{0}}-\frac{P}{\Delta_{p}}\right)-R^{F}} \\
B_{0 j}^{S 0 *} & =\frac{P}{\Delta_{p}} \frac{A}{1-p_{H}\left(\Delta_{R_{0}}-\frac{P}{\Delta_{p}}\right)-R^{F}}=\frac{P I_{0 j}^{0 *}}{\Delta_{p}} \\
B_{0 j}^{F 0 *} & =0 .
\end{aligned}
$$

Proof. See the appendix A.1.

The implications of the formulas in Lemma 2 are the usual ones in these kinds of models. From (12), firms' borrowing capacity $I_{0 j}^{0 *}$ is increasing in tangible assets $A$, i.e. the higher is $A$, the lower is credit rationing. Borrowing capacity $I_{0 j}^{0 *}$ is also decreasing in agency costs (private benefit, $P$, or inverse likelihood ratio, $\left.\frac{p_{H}}{\Delta_{p}}\right)$. The fact that $B_{0 j}^{F 0 *}=0$, instead, implies that the optimal contract is a debt one, which gives the highest incentives of behaving to the entrepreneur, which is the well known Jensen and Meckling (1976) result.

\subsubsection{Motivated borrowers undertaking ethical projects}

We first consider the optimal contract signed by motivated borrowers undertaking ethical projects financed by standard banks. Remind that, in this case, the premium for social responsibility is $\theta_{01}^{S 1}=\theta_{01}^{F 1}=\theta$. Interestingly, we will show that standard banks offer the same contract to both types of borrowers, despite the fact that the premium $\theta$, accruing motivated borrowers investing in ethical projects, becomes active in this case.

The contract between a motivated borrower and a standard bank when undertaking an ethical project is denoted by $\left(B_{01}^{S 1}, B_{01}^{F 1}, I_{01}^{1}\right)$. In this case the borrowers' incentive compatibility constraint is $\left(I C_{01}^{B 1}\right)$ :

$$
\begin{gathered}
p_{H} \cdot\left(B_{01}^{S 1}+\theta\right)+\left(1-p_{H}\right)\left(B_{01}^{F 1}+\theta\right)-A \geq \\
p_{L} \cdot\left(B_{01}^{S 1}+\theta\right)+\left(1-p_{L}\right)\left(B_{01}^{F 1}+\theta\right)+P \cdot I_{01}^{1}-A
\end{gathered}
$$

or

$$
p_{H} \cdot B_{01}^{S 1}+\left(1-p_{H}\right) B_{01}^{F 1} \geq p_{L} \cdot B_{01}^{S 1}+\left(1-p_{L}\right) B_{01}^{F 1}+P \cdot I_{01}^{1}
$$


that is:

$$
\Delta_{B_{01}^{1}} \geq \frac{P I_{01}^{1}}{\Delta_{p}}
$$

where $\Delta_{B_{01}^{1}}=B_{01}^{S 1}-B_{01}^{F 1}$. Note that, since the premium $\theta$ has no impact on the incentive compatibility constraint of the motivated borrower, (13) is similar to constraint (8) before. ${ }^{13}$ We can state:

Remark 1 The premium for social responsibility $\theta$ affects the payoff of the motivated borrower but not the contract that she signs with the standard bank; thus, in the case of ethical projects, standard lenders offer the same contract to both types of borrowers, or $\left(B_{00}^{S 1 *}, B_{00}^{F 1 *}, I_{00}^{1 *}\right)=\left(B_{01}^{S 1 *}, B_{01}^{F 1 *}, I_{01}^{1 *}\right)=\left(B_{0 j}^{S 1 *}, B_{0 j}^{F 1 *}, I_{0 j}^{1 *}\right)$.

We now consider contracts $\left(B_{11}^{S 1}, B_{11}^{F 1}, I_{11}^{1}\right)$ that are designed for motivated borrowers interacting with ethical banks. Recall that $\Delta_{\theta}$ is the premium for successful interaction that a motivated borrower obtains when trading with an ethical bank in the case of successful project. Thus, the incentive compatibility constraint of a motivated borrower trading with an ethical bank writes:

$$
\begin{gathered}
p_{H}\left(B_{11}^{S 1}+\theta+\Delta_{\theta}\right)+\left(1-p_{H}\right)\left(B_{11}^{F 1}+\theta\right)-A \geq \\
p_{L}\left(B_{11}^{S 1}+\theta+\Delta_{\theta}\right)+\left(1-p_{L}\right)\left(B_{11}^{F 1}+\theta\right)+P I_{11}^{1}-A
\end{gathered}
$$

that is:

$$
\Delta_{B_{11}^{1}}+\Delta_{\theta} \geq \frac{P I_{11}^{1}}{\Delta_{p}}
$$

where $\Delta_{B_{11}^{1}}=B_{11}^{S 1}-B_{11}^{F 1}$.

If $\Delta_{\theta}$ is sufficiently high, the previous incentive compatibility constraint is more easily satisfied than the one before (see inequality 13). In different words, if the premium for successful interaction $\Delta_{\theta}$ is sufficient to compensate ethical projects' low profitability, ethical banks and motivated borrowers interacting together can implement more efficient contracts, as we show below.

Considering the motivated borrowers' choice whether to invest in ethical projects either with a standard or with an ethical bank we can state:

\footnotetext{
${ }^{13}$ Thus, both standard and motivated borrowers trading with a commercial bank receive a contract with higher borrowing capacity and higher expected profit if they undertake a standard project. However, since motivated borrowers undertaking an ethical project with a standard bank also receive the premium $\theta$, they could nevertheless prefer an ethical project with worse borrowing condition $\left(B_{0 j}^{S 1 *}, B_{0 j}^{F 1 *}, I_{0 j}^{1 *}\right)$ to a standard one under the contract $\left(B_{0 j}^{S 0 *}, B_{0 j}^{F 0 *}, I_{0 j}^{0 *}\right)$. A sufficient condition is that the social responsibility parameter $\theta$ is high enough, in particular:$$
\theta \geq p_{H}^{2} \frac{P}{\Delta_{p}} \frac{A}{1-p_{H}\left(\Delta_{R_{0}}-\frac{P}{\Delta_{p}}\right)-R^{F}} \frac{\Delta_{R_{0}}-\Delta_{R_{1}}}{1-p_{H}\left(\Delta_{R_{1}}-\frac{P}{\Delta_{p}}\right)-R^{F}}=\underline{\theta}
$$

Condition (14) is obtained considering that the motivated borrower prefers the ethical project financed by a standard bank to a standard one if the following inequality holds:

$$
p_{H} \Delta_{B_{01}^{1}}+B_{01}^{F 1}+\theta-A \geq p_{H} \Delta_{B_{00}^{0}}+B_{00}^{F 0}-A
$$

(14) is a direct consequence of the previous inequality after substituting the values appearing in the optimal contracts $\left(B_{00}^{S 0 *}, B_{00}^{F 0 *}, I_{00}^{0 *}\right)$ and $\left(B_{01}^{S 1 *}, B_{01}^{F 1 *}, I_{01}^{1 *}\right)$.
} 
Remark 2 When undertaking an ethical project, motivated borrowers will always prefer to trade with an ethical bank rather than with a standard lender. In fact, interacting with an ethical bank, they obtain a contract that is at least as profitable as the one they can obtain from a standard bank and they also receive the premium $\Delta_{\theta}$ for successful interaction.

Despite the presence of the premium for successful interaction $\Delta_{\theta}$, we can follow the same steps as in the previous cases. In particular, the problem of a representative motivated borrower trading with an ethical bank is:

$$
\begin{array}{ccc}
\max _{\Delta_{B_{11}^{1}}, B_{11}^{F 1}, I_{11}^{1}} & p_{H} \Delta_{B_{11}^{1}}+p_{H} \Delta_{\theta}+\theta+B_{11}^{F 1}-A & \\
\text { s.t. } & \Delta_{B_{11}^{1}}+\Delta_{\theta} \geq \frac{P I_{11}^{1}}{\Delta_{p}} & \left(I C_{11}^{B 1}\right) \\
& \left(p_{H} \Delta_{R_{1}}+R^{F}-1\right) I_{11}^{1}-p_{H} \Delta_{B_{11}^{1}}- & \left(I R_{11}^{L 1}\right) \\
& B_{11}^{F 1}+A \geq 0 &
\end{array}
$$

The optimal contract is characterized as follows:

Lemma 3 The contract for a motivated borrower trading with an ethical bank under moral-hazard is a debt contract $\left(B_{11}^{S 1 *}, B_{11}^{F 1 *}, I_{11}^{1 *}\right)$ such that:

$$
\begin{aligned}
I_{11}^{1 *} & =\frac{A+p_{H} \Delta_{\theta}}{1-p_{H}\left(\Delta_{R_{1}}-\frac{P}{\Delta_{p}}\right)-R^{F}} \\
B_{11}^{S 1 *} & =\frac{P}{\Delta_{p}} \frac{A+p_{H} \Delta_{\theta}}{1-p_{H}\left(\Delta_{R_{1}}-\frac{P}{\Delta_{p}}\right)-R^{F}}-\Delta_{\theta} \\
B_{11}^{F 1 *} & =0
\end{aligned}
$$

Proof. See the appendix A.2.

Note that, in the debt contract $\left(B_{11}^{S 1 *}, B_{11}^{F 1 *}, I_{11}^{1 *}\right)$, the premium for successful interaction $\Delta_{\theta}$ positively affects the borrowing capacity $I_{11}^{1 *}$ of the motivated investors, while its impact on the expected return in case of success $B_{11}^{S 1 *}$ is ambiguous.

From results in this and in the previous subsection we learnt the following: standard borrowers always sign a contract with a standard bank for a standard project, whereas motivated borrowers can either sign the very same contract or they can invest in an ethical project with an ethical bank. Thus, as we anticipated before, the market structure arising at the equilibrium depends on the motivated borrowers' choice between investing in a standard project with a standard bank or in an ethical one with an ethical bank.

In order to find out conditions such that a motivated borrower prefers to undertake an ethical project with an ethical bank than a standard project with a standard bank, the next step will be to compare contracts $\left(B_{11}^{S 1 *}, B_{11}^{F 1 *}, I_{11}^{1 *}\right)$ and $\left(B_{0 j}^{S 0 *}, B_{0 j}^{F 0 *}, I_{0 j}^{0 *}\right)$ and the motivated borrowers' pay-off under the two contracts. As we will see, since the ethical bank is more efficient in solving the moral hazard problem of the motivated borrowers, it is possible that ethical banks offer better contract conditions even if ethical projects imply lower expected returns. 


\subsection{The Equilibrium under pure moral hazard}

The comparison of the two contracts $\left(B_{11}^{S 1 *}, B_{11}^{F 1 *}, I_{11}^{1 *}\right)$ and $\left(B_{0 j}^{S 0 *}, B_{0 j}^{F 0 *}, I_{0 j}^{0 *}\right)$ allows us to compute a few critical levels for the parameter of successful interaction $\Delta_{\theta}$ which will be useful to characterize the equilibrium.

Lemma 4 Motivated borrowers trading with an ethical bank:

- have a higher borrowing capacity than when undertaking a standard project with a standard lender $\left(I_{11}^{1 *}>I_{0 j}^{0 *}\right)$ if:

$$
\Delta_{\theta} \geq\left(\Delta_{R_{0}}-\Delta_{R_{1}}\right) I_{0 j}^{0 *} \equiv \underline{\Delta}_{\theta}
$$

- obtain higher expected net profits than when undertaking a standard project with a standard lender $\left(B_{11}^{S 1 *}>B_{0 j}^{S 0 *}\right)$ if:

$$
\Delta_{\theta} \geq \frac{p_{H} P}{\Delta_{p}} \frac{\left(\Delta_{R_{0}}-\Delta_{R_{1}}\right) I_{0 j}^{0 *}}{p_{H} \Delta_{R_{1}}+R^{F}-1}=\frac{p_{H} B_{0 j}^{S 0 *}}{p_{H} \Delta_{R_{1}}+R^{F}-1}\left(\Delta_{R_{0}}-\Delta_{R_{1}}\right) \equiv \bar{\Delta}_{\theta}
$$

where condition (19) implies condition (18), or $\underline{\Delta}_{\theta}<\bar{\Delta}_{\theta}$.

Proof. See the Appendix A.3.

As one can check, both conditions (18) and (19) require that the expected profit from the ethical projects is not too small compared to that from the other projects $\left(\Delta_{R_{0}}-\Delta_{R_{1}}\right.$ is low $)$, or that the premium for successful interaction $\Delta_{\theta}$ is high enough.

The first condition, $\Delta_{\theta} \geq \underline{\Delta}_{\theta}$, in Lemma 4 has a simple interpretation. The premium for successful interaction has to be greater than the difference in expected revenue between standard and ethical projects, for unit of investment. If this condition holds, in a sense, the motivation of the agents acts as an additional collateral, that we may call "ethical collateral".

The second condition, $\Delta_{\theta} \geq \bar{\Delta}_{\theta}$, is more tricky to interpret. The ratio $\frac{\left(\Delta_{R_{0}}-\Delta_{R_{1}}\right) I_{0 j}^{0 *}}{p_{H} \Delta_{R_{1}}+R^{F}-1}$ is the rate of increase in profitability from ethical to standard projects with respect to the profit of the ethical project, while the term $\frac{p_{H} P}{\Delta_{p}}$ represents the agency costs to be paid for letting standard borrowers commit to a correct behavior, $\frac{P}{\Delta_{p}}$, weighted for the probability of having to bear those costs, $p_{H}$. Summarizing, $\bar{\Delta}_{\theta}$ represents the agency cost that the standard borrower has to pay in order to (make it credible to) behave, weighted for the expected rate of increase of profitability in turning to a standard project.

Lemma 4 allows us to fully compare the two contracts $\left(B_{0 j}^{S 0 *}, B_{0 j}^{F 0 *}, I_{0 j}^{0 *}\right)$ and $\left(B_{11}^{S 1 *}, B_{11}^{F 1 *}, I_{11}^{1 *}\right)$ depending on the magnitude of the premium for successful interaction $\Delta_{\theta}$. If the premium for successful interaction is high, $\Delta_{\theta} \geq \bar{\Delta}_{\theta}$, motivated borrowers trading with ethical banks receive a contract characterized by higher expected profits $\left(B_{11}^{S 1 *}>B_{0 j}^{S 0 *}\right)$ and higher borrowing capacity $\left(I_{11}^{1 *}>I_{0 j}^{0 *}\right)$ than when trading with a standard bank. In fact, the relationship becomes very efficient in solving the moral hazard problem and this more than 
compensates the lower expected revenue of ethical projects. The opposite situation arises when the premium for successful interaction is low, $\Delta_{\theta}<\Delta_{\theta}$ : motivated borrowers trading with ethical banks receive a contract with lower expected profits $\left(B_{11}^{S 1 *}<B_{0 j}^{S 0 *}\right)$ and lower borrowing capacity $\left(I_{11}^{1 *}<I_{0 j}^{0 *}\right)$ than when trading with a standard bank. Here the lower expected returns from ethical projects prevails over the benefit from solving the moral hazard problem more efficiently. If $\Delta_{\theta}$ belongs to an intermediate range, $\underline{\Delta}_{\theta} \leq \Delta_{\theta} \leq \bar{\Delta}_{\theta}$, then the motivated borrowers get a lower expected profit $\left(B_{11}^{S 1 *}<B_{0 j}^{S 0 *}\right)$, but a higher borrowing capacity $\left(I_{11}^{1 *}>I_{0 j}^{0 *}\right)$ by dealing with an ethical bank.

Now we can finally obtain the preferred choice of the motivated borrowers. Obviously, if $\Delta_{\theta} \geq \bar{\Delta}_{\theta}$, then motivated borrowers prefer to trade with socially responsible lenders since, by doing so, they can both benefit from the total premium for social responsibility $p_{H} \Delta \theta+\theta$ and from a higher expected revenue $B_{11}^{S 1 *}$. Moreover, it is easy to check that motivated borrowers prefer to trade with ethical banks even when $\underline{\Delta}_{\theta} \leq \Delta_{\theta} \leq \bar{\Delta}_{\theta}$.

Suppose now that $\Delta_{\theta}<\underline{\Delta}_{\theta}$. Motivated borrowers receive in this case a higher loan and a higher expected profit when they undertake a standard project contracting with standard lenders. However, they still prefer to trade with socially responsible banks if the total premium for social responsibility $p_{H} \Delta_{\theta}+\theta$ more than compensates the lower expected profit:

Lemma 5 Motivated borrowers prefer to contract with ethical banks than with standard ones for $\Delta_{\theta} \geq \widetilde{\Delta}_{\theta}(\theta)$, where:

$$
\widetilde{\Delta}_{\theta}(\theta)=\max \left\{0, \Delta_{\theta}-\frac{\Delta_{p}}{p_{H}^{2} P}\left(1-p_{H}\left(\Delta_{R_{1}}-\frac{P}{\Delta_{p}}\right)-R^{F}\right) \theta\right\}
$$

with $\widetilde{\Delta}_{\theta}(\theta)$ decreasing in $\theta$ when strictly positive, and $\widetilde{\Delta}_{\theta}(\theta) \leq \underline{\Delta}_{\theta} \forall \theta$.

If $\theta=0$, then $\widetilde{\Delta}_{\theta}(\theta)=\underline{\Delta}_{\theta}$ and the necessary condition for motivated borrowers to trade with socially responsible lenders is more stringent.

Proof. See the Appendix A.4.

The previous Lemma shows that motivated borrowers will accept a loan from ethical banks if the premium for successful interaction $\Delta_{\theta}$ is higher than the threshold value $\widetilde{\Delta}_{\theta}(\theta)$ which depends on $\theta$. In particular, $\widetilde{\Delta}_{\theta}(\theta)$ is decreasing in $\theta$ and is always weakly lower than $\Delta_{\theta}$. Namely, if $\Delta_{\theta} \geq \widetilde{\Delta}_{\theta}(\theta)$, then motivated borrowers prefer to trade with socially responsible lenders even if this implies signing the worst contract. Thus, if $\Delta_{\theta} \geq \widetilde{\Delta}_{\theta}(\theta)$, the contract $\left(B_{0 j}^{S 0 *}, B_{0 j}^{F 0 *}, I_{0 j}^{0 *}\right)$ can be indicated as $\left(B_{00}^{S 0 *}, B_{00}^{F 0 *}, I_{00}^{0 *}\right)$ since it is signed only by standard borrowers. As a consequence the market is fully segmented in that case.

When on the contrary $\Delta_{\theta}<\widetilde{\Delta}_{\theta}(\theta)$, motivated borrowers will prefer to trade with standard lenders since the total premium $p_{H} \Delta_{\theta}+\theta$ is not enough to compensate the worst contract conditions. This implies that ethical banks are not active in the credit market in this case. 
Interestingly, given condition (20) and if the premium for social responsibility $\theta$ is zero, then $\widetilde{\Delta}_{\theta}(\theta)=\underline{\Delta}_{\theta}$ and motivated borrowers prefer to trade with socially responsible lenders only if, by doing so, they receive at least a higher borrowing capacity $\left(I_{11}^{1 *}>I_{0 j}^{0 *}\right)$.

Note also that, if the premium for social responsibility $\theta$ is sufficiently high, then $\widetilde{\Delta}_{\theta}(\theta)$ in $(20)$ becomes zero and we obtain a situation where motivated borrowers always prefer to trade with ethical banks, whatever the premium for successful interaction.

The following proposition summarizes results in Section 3:

Proposition 1 Moral hazard. Suppose that borrowers' type is observable, but lenders cannot observe the borrowers' behavior.

- When $\Delta_{\theta} \geq \widetilde{\Delta}_{\theta}(\theta)$, then the credit market is fully segmented and the debt contracts $\left(B_{00}^{S 0 *}, B_{00}^{F 0 *}, I_{00}^{0 *}\right)$ and $\left(B_{11}^{S 1 *}, B_{11}^{F 1 *}, I_{11}^{1 *}\right)$ are signed by standard and motivated borrowers respectively.

1. If $\Delta_{\theta} \geq \bar{\Delta}_{\theta}$, then the contracts are such that $I_{11}^{1 *}>I_{00}^{0 *}$ and $B_{11}^{S 1 *}>$ $B_{00}^{S O *}$.

2. If $\underline{\Delta}_{\theta} \leq \Delta_{\theta} \leq \bar{\Delta}_{\theta}$, the contracts are such that: $I_{11}^{1 *}>I_{00}^{0 *}$ and $B_{11}^{S 1 *}<$ $B_{00} \stackrel{\Delta}{S 0 *}$.

3. If $\widetilde{\Delta}_{\theta}(\theta)<\Delta_{\theta} \leq \Delta_{\theta}$, the contracts are such that: $I_{11}^{1 *}<I_{00}^{0 *}$ and $B_{11}^{S 1 *}<B_{00}^{S 0 *}$.

- When $0 \leq \Delta_{\theta}<\widetilde{\Delta}_{\theta}(\theta)$, then socially responsible banks are not active and the market for ethical projects does not exist: all borrowers accept the contract $\left(B_{0 j}^{S 0 *}, B_{0 j}^{F 0 *}, I_{0 j}^{0 *}\right)$ offered by standard lenders.

Proposition 1 shows that, if $\Delta_{\theta} \geq \widetilde{\Delta}_{\theta}(\theta)$, two separated credit markets are created: one market for ethical projects where only agents aware of social issues trade with each other and one for standard projects where only standard agents operate. In fact, when the premium for successful interaction is sufficiently high (and $\theta$ is strictly positive), then the total premium for social responsibility $p_{H} \Delta_{\theta}+\theta$ more than compensates the worse contract conditions so that motivated borrowers prefer to undertake ethical projects contracting with ethical banks.

Interestingly, when $\theta=0$, conditions for market segmentation are stricter $\left(\widetilde{\Delta}_{\theta}(\theta) \equiv \underline{\Delta}_{\theta}\right)$ since motivated borrowers trade with ethical banks only if they receive a contract at least characterized by higher borrowing capacity: $I_{11}^{1 *}>I_{00}^{0 *}$.

On the contrary, if $\widetilde{\Delta}_{\theta}(\theta)=0$, meaning that $\theta$ is relatively large, then the ethical banks are always active because the premium for social responsibility is so high that the motivated borrowers always prefer an ethical project to a standard one, even if the premium for successful interaction is nought. We will discuss this possibility at the end of this section.

Note that, when the premium for successful interaction is sufficiently high $\left(\Delta_{\theta} \geq \bar{\Delta}_{\theta}\right)$, motivated borrowers obtain a contract that is more profitable than 
the one signed by the standard borrowers, since the matching between agents aware of social issues allows the inefficiency due to moral hazard to decrease. The result obtained for $\Delta_{\theta} \geq \bar{\Delta}_{\theta}$ is perfectly in line with Besley and Ghatak's (2005), where mission oriented workers perfectly match with mission oriented firms of the same type and social productivity increases.

When $0 \leq \Delta_{\theta}<\widetilde{\Delta}_{\theta}(\theta)$, then the market for ethical projects does not exist since the total premium for social responsibility $p_{H} \Delta_{\theta}+\theta$ is not sufficient to compensate the lower expected profits from ethical projects. In such a case, motivated borrowers behave exactly as standard ones and both the efficiency gain from assortative matching and the social benefit from ethical projects are fully lost. ${ }^{14}$

Our results are summarized in Figure 1 below. In the figure, the relative expected profitability of standard and ethical projects is taken as given and the threshold values characterized in Lemmas 4 and 5 are depicted. The second best contracts are compared and the market segmentation is illustrated as a function of the premium for successful interaction $\Delta_{\theta}$.

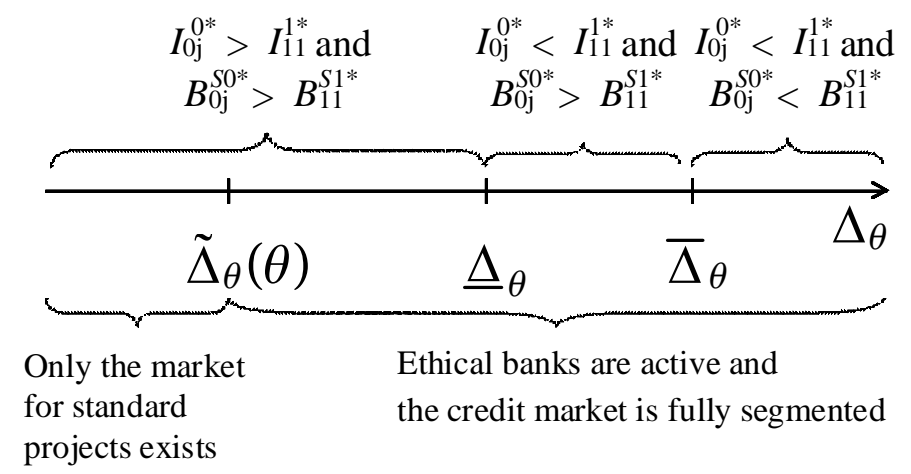

Figure 1. Pure moral hazard (second-best): given the relative expected returns of standard and ethical projects, second-best contracts depend on the magnitude of the premium for successful interaction as illustrated in Proposition 1.

$\Delta_{\theta}$ We conclude this section with some remarks on the role exerted by $\theta$ and $\Delta_{\theta}$ in our model. Recall that the term $p_{H} \Delta_{\theta}+\theta$ represents the total premium for social responsibility possibly received by motivated borrowers. Since the premium for successful interaction $\Delta_{\theta}$ is multiplied by the probability $p_{H}$, its contribution to the total premium for social responsibility is lower than the one of $\theta$. However, note that the beneficial effect of the matching between agents aware of social issues is totally driven by the premium for successful interaction $\Delta_{\theta}$. Indeed all our results still hold when $\theta=0$, that is when motivated borrow-

\footnotetext{
${ }^{14}$ This result is driven, among other things, by the discrete nature of the choice between profit maximizing and ethical projects and contrasts with Besley and Ghatak (2007) where caring consumers always delegate to firms the production of a positive amount of the public good, which is represented by a continuous variable.
} 
ers do not receive any premium for undertaking ethical projects with standard banks. ${ }^{15}$ We can conclude that the premium for successful interaction has a low direct impact on expected utility of motivated borrowers, nevertheless it represents the crucial ingredient in our model.

Considering again our results when $\theta=0$, the region where ethical banks are not active always exists, in this case, and corresponds to $\Delta_{\theta} \in\left[0, \widetilde{\Delta}_{\theta}(\theta)=\Delta_{\theta}\right]$. On the contrary, when the premium $\theta$ is strictly positive, in principle it can be $\widetilde{\Delta}_{\theta}(\theta)=0$ implying that ethical banks are always active. However, the scenario where ethical banks always exist is not particularly interesting nor particularly reasonable, since motivated borrowers, in this case, are willing to invest in ethical projects "by definition". As it was mentioned in Section 2, we find it more realistic to assume that motivated borrowers are willing to undertake ethical projects as long as their social engagement is not too costly in terms of material payoffs. Put it differently, we expect motivated borrowers to behave as standard ones when the gains in profits are sufficiently high. This implies that, in our view, the premium $\theta$ should be sufficiently low with respect to the difference in projects' profitability to assure that a region where ethical banks are not active also exists when $\theta$ is strictly positive, or:

$0 \leq \theta \leq \frac{p_{H}^{2} P\left(\Delta_{R_{0}}-\Delta_{R_{1}}\right) A}{\Delta_{p}\left(1-p_{H}\left(\Delta_{R_{0}}-\frac{P}{\Delta_{p}}\right)-R^{F}\right)\left(1-p_{H}\left(\Delta_{R_{1}}-\frac{P}{\Delta_{p}}\right)-R^{F}\right)}=\theta_{\max }$

where $\theta_{\max }$ is the value of the premium for social responsibility such that the threshold value $\widetilde{\Delta}_{\theta}(\theta)$ is zero. ${ }^{16}$

\section{Loan Agreements under Moral Hazard and Adverse Selection}

We consider here the following information structure: lenders' corporate social responsibility is common knowledge, but lenders cannot observe neither the borrowers' behavior nor the borrowers' motivation. As already mentioned, this setting fits a situation where lenders are banks with well known characteristics, while borrowers are new firms without reputation. This environment is interesting since, when the premium for successful interaction is sufficiently high, motivated borrowers trading with ethical banks obtain better contract conditions than standard borrowers trading with standard lenders (see Proposition 1 above). Thus, standard borrowers could take advantage of their private information by pretending to be motivated. In this latter case ethical banks could

\footnotetext{
${ }^{15} \theta=0$ was precisely our assumption in a previous version of the paper.

${ }^{16}$ In particular, the value $\theta_{\max }$ satisfies:

$$
\underline{\Delta}_{\theta}-\frac{\Delta_{p}}{p_{H}^{2} P}\left(1-p_{H}\left(\Delta_{R_{1}}-\frac{P}{\Delta_{p}}\right)-R^{F}\right) \theta=\widetilde{\Delta}_{\theta}(\theta)=0
$$
}

(see the end of Appendix A.4). 
obtain negative profits, since standard borrowers mimicking motivated ones possibly misbehave, which amount to saying that the contract $\left(B_{11}^{S 1 *}, B_{11}^{F 1 *}, I_{11}^{1 *}\right)$ is not necessarily incentive compatible for standard borrowers.

Lenders here know that the percentage of motivated borrowers in the credit market is $q$ whereas that of standard ones is $1-q$. We call this game the thirdbest.

To solve the model with both moral hazard and adverse selection on the borrowers' type we proceed as follows. (i) We show that the third-best contract corresponds to the second best when $\Delta_{\theta}<\bar{\Delta}_{\theta}$. (ii) We characterize the self-selecting contracts for $\Delta_{\theta} \geq \bar{\Delta}_{\theta}$ and we show that, at the equilibrium, standard borrowers receive the second-best contract $\left(B_{0 j}^{S 0 *}, B_{0 j}^{F 0 *}, I_{0 j}^{0 *}\right)$ whereas motivated ones receive the third-best contract $\left(B_{11}^{S 1 * *}, B_{11}^{F 1 * *}, I_{11}^{1 * *}\right)$, which is distorted with respect to $\left(B_{11}^{S 1 *}, B_{11}^{F 1 *}, I_{11}^{1 *}\right)$. (iii) We find a sufficient condition such that the equilibrium contracts $\left(B_{0 j}^{S 0 *}, B_{0 j}^{F 0 *}, I_{0 j}^{0 *}\right)$ and $\left(B_{11}^{S 1 * *}, B_{11}^{F 1 * *}\right.$, $\left.I_{11}^{1 * *}\right)$ are (constrained) efficient. Finally, (iv) we conclude that also existence is assured when the previous condition is met. Notice that borrowers are the informed party. Therefore we are considering a case similar to that of contract design by an informed principal (see Maskin and Tirole 1992 and also Tirole 2006, page 264). However, our problem is slightly different. On the one hand, this problem is more complicated because we also have moral-hazard and there are two types of agents (the ethical and the profit maximizing bank). On the other hand our model is simpler, because competition among banks allows us to restrict the attention to optimal contracts, as discussed in the end of the section, that is, we can restrict our attention to what Tirole (2006, page 264) defines the "low-information-intensity optimum".

Since borrowers' motivation is part of the borrowers' private information, in the new set-up we have to consider also the self-selection constraint. Obviously, if second-best contracts $\left(B_{0 j}^{S 0 *}, B_{0 j}^{F 0 *}, I_{0 j}^{0 *}\right)$ and $\left(B_{11}^{S 1 *}, B_{11}^{F 1 *}, I_{11}^{1 *}\right)$ defined before verify such a self-selection constraint, then those contracts can also be offered in third-best (they are envy free).

From Proposition 1, all borrowers' types prefer contract $\left(B_{0 j}^{S 0 *}, B_{0 j}^{F 0 *}, I_{0 j}^{0 *}\right)$ in the second best, if $\Delta_{\theta}<\widetilde{\Delta}_{\theta}(\theta)$. In this case ethical banks are not active and the two borrowers' types become identical since motivated borrowers do not receive any premium for social responsibility. Therefore, Proposition 1 implies straightforwardly that, when $\Delta_{\theta}<\widetilde{\Delta}_{\theta}(\theta)$, standard lenders offer the secondbest contract $\left(B_{0 j}^{S 0 *}, B_{0 j}^{F 0 *}, I_{0 j}^{0 *}\right)$ to all borrowers, also in the third best.

Let us consider now higher levels of the premium for successful interaction and check whether borrowers have incentive to lie. From Proposition 1 we know that, in second-best, motivated borrowers prefer contract $\left(B_{11}^{S 1 *}, B_{11}^{F 1 *}, I_{11}^{1 *}\right)$ to contract $\left(B_{0 j}^{S 0 *}, B_{0 j}^{F 0 *}, I_{0 j}^{0 *}\right)$ when $\Delta_{\theta} \geq \widetilde{\Delta}_{\theta}(\theta)$. Moreover, standard borrowers prefer contract $\left(B_{0 j}^{S 0 *}, B_{0 j}^{F 0 *}, I_{0 j}^{0 *}\right)$ to contract $\left(B_{11}^{S 1 *}, B_{11}^{F 1 *}, I_{11}^{1 *}\right)$ when $\Delta_{\theta} \leq \bar{\Delta}_{\theta}$ since, with the first contract, they receive a higher expected utility than with the latter one. In fact:

$$
p_{H} \Delta_{B_{0 j}^{0 *}}+B_{0 j}^{F 0 *}-A>p_{H} \Delta_{B_{11}^{1 *}}+B_{11}^{F 1 *}-A
$$


where $\Delta_{B_{0 j}^{0 *}}>\Delta_{B_{11}^{1 *}}$.

Summarizing, from the previous reasoning we know that when $\widetilde{\Delta}_{\theta}(\theta) \leq$ $\Delta_{\theta} \leq \bar{\Delta}_{\theta}$, the second best contracts $\left(B_{0 j}^{S 0 *}, B_{0 j}^{F 0 *}, I_{0 j}^{0 *}\right) \equiv\left(B_{00}^{S 0 *}, B_{00}^{F 0 *}, I_{00}^{0 *}\right)$ and $\left(B_{11}^{S 1 *}, B_{11}^{F 1 *}, I_{11}^{1 *}\right)$ are envy free and can also be offered in third-best. In this case the credit market is fully segmented and no distortions are necessary to separate borrowers' types. Whereas, when $\Delta_{\theta}<\widetilde{\Delta}_{\theta}(\theta)$, only standard lenders are active in the credit market and the second-best contract $\left(B_{0 j}^{S 0 *}, B_{0 j}^{F 0 *}, I_{0 j}^{0 *}\right)$ is offered to both borrowers' types.

We consider now the most interesting case where $\Delta_{\theta} \geq \bar{\Delta}_{\theta}$, that is, the premium for successful interaction more than compensates ethical projects' low profitability. Here both borrowers' types prefer contract $\left(B_{11}^{S 1 *}, B_{11}^{F 1 *}, I_{11}^{1 *}\right)$ since the latter leads to a higher expected utility than $\left(B_{0 j}^{S 0 *}, B_{0 j}^{F 0 *}, I_{0 j}^{0 *}\right)$.

Again, because of the assumption of Bertrand competition among (both types of) lenders, borrowers are endowed with all the bargaining power and obtain all the surplus from trade in equilibrium. Thus, we can solve the model as in Section 3 by finding the optimal contract for the borrowers under both their incentive compatibility and their self-selection constraint.

Note that in third-best, also when $\Delta_{\theta}>\bar{\Delta}_{\theta}$, commercial banks still offer the second-best contract $\left(B_{0 j}^{S 0 *}, B_{0 j}^{F 0 *}, I_{0 j}^{0 *}\right)$ since all borrowers are the same when trading with standard lenders and no adverse selection issues arise:

Lemma 6 In third-best, standard banks offer the second-best contract $\left(B_{0 j}^{S 0 *}\right.$, $\left.B_{0 j}^{F 0 *}, I_{0 j}^{0 *}\right)$ whatever the size of the premium for successful interaction, $\Delta_{\theta}$.

Instead, when $\Delta_{\theta} \geq \bar{\Delta}_{\theta}$, ethical banks must offer a self-selecting contract to prevent standard borrowers from mimicking motivated ones and possibly misbehaving.

The separating allocation with no cross subsidization between types of borrowers offered by ethical banks is the contract $\left(B_{11}^{S 1 * *}, B_{11}^{F 1 * *}, I_{11}^{1 * *}\right)$ for motivated borrowers and the second-best contract $\left(B_{10}^{S 1 *}, B_{10}^{F 1 *}, I_{10}^{1 *}\right)$ for standard ones ${ }^{17}$. The contract $\left(B_{11}^{S 1 * *}, B_{11}^{F 1 * *}, I_{11}^{1 * *}\right)$ maximizes motivated borrowers' payoff subject to the motivated borrower's incentive compatibility constraint, the ethical lender's participation constraint and subject to standard borrowers not preferring $\left(B_{11}^{S 1 * *}, B_{11}^{F 1 * *}, I_{11}^{1 * *}\right)$ to $\left(B_{10}^{S 1 *}, B_{10}^{F 1 *}, I_{10}^{1 *}\right)$. A detailed discussion on the self-selection constraint will follow.

\footnotetext{
${ }^{17}$ Note that the second-best contract $\left(B_{10}^{S 1 *}, B_{10}^{F 1 *}, I_{10}^{1 *}\right)$ was not part of the second-best equilibrium described in Proposition 1 since standard borrowers always prefer to undertake standard projects with standard banks when their type is observable. Nevertheless, here we are looking for the self-selecting contracts offered by ethical banks and thus we must consider the two contracts that ethical banks design for the two types of existing borrowers. However, in order to decrease distortions necessary for separation of types, in a few lines we will consider again the contract obtained in the second-best equilibrium $\left(B_{00}^{S 0 *}, B_{00}^{F 0 *}, I_{00}^{0 *}\right)$ (see constraint 22).
} 
The program writes:

$$
\begin{array}{ccc}
\max _{\Delta_{B_{11}^{1}}^{1}, B_{11}^{F 1}, I_{11}^{1}} & p_{H} \Delta_{B_{11}^{1}}+p_{H} \Delta_{\theta}+\theta+B_{11}^{F 1}-A & \\
\text { s.t. } & \Delta_{B_{11}^{1}}+\Delta_{\theta} \geq \frac{P}{\Delta_{p}} I_{11}^{1} & \left(I C_{11}^{B 1}\right) \\
& \left(p_{H} \Delta_{R_{1}}+R^{F}-1\right) I_{11}^{1} & \left(I R_{11}^{L 1}\right) \\
& -p_{H} \Delta_{B_{11}^{1}}-B_{11}^{F 1}+A \geq 0 & \left(S S_{1}^{B 1}\right)
\end{array}
$$

From Lemma 1 a standard borrower always prefers contract $\left(B_{0 j}^{S 0 *}, B_{0 j}^{F 0 *}, I_{0 j}^{0 *}\right)$ to contract $\left(B_{10}^{S 1 *}, B_{10}^{F 1 *}, I_{10}^{1 *}\right)$, since standard projects have higher expected returns. Thus, a standard borrower will never choose the second-best contract $\left(B_{10}^{S 1 *}, B_{10}^{F 1 *}, I_{10}^{1 *}\right)$ in the third-best equilibrium, it will instead sign the preferred contract $\left(B_{0 j}^{S 0 *}, B_{0 j}^{F 0 *}, I_{0 j}^{0 *}\right)$ with standard banks. For this reason we can consider the following modified self-selection constraint where $B_{0 j}^{S 0 *}$ is substituted to $B_{10}^{S 1 *}$ in the l.h.s. of the inequality $\left(S S_{1}^{B 1}\right)$ :

$$
p_{H} B_{0 j}^{S 0 *} \geq p_{L} \Delta_{B_{11}^{1}}+B_{11}^{F 1}+P I_{11}^{1}
$$

Since $B_{0 j}^{S 0 *}>B_{10}^{S 1 *}$, the previous substitution allows us to impose a lower distortion to contract $\left(B_{11}^{S 1 * *}, B_{11}^{F 1 * *}, I_{11}^{1 * *}\right)$ in order to obtain separation.

Note that, both in the self-selection constraints $\left(S S_{1}^{B 1}\right)$ and in inequality (22), the mimicker misbehaves $(a=0)$, so that, in the right-hand-side of the inequality, the probability of a successful investment is only $p_{L}$. To understand why, consider that an ethical bank is in principle indifferent with respect to the type of investors that are undertaking ethical projects. In other words, if the contract $\left(B_{11}^{S 1 * *}, B_{11}^{F 1 * *}, I_{11}^{1 * *}\right)$ is signed by either a standard or a motivated borrower, the ethical bank is equally satisfied, provided that the borrower behaves. The necessity to design a separate contract for motivated and for standard borrowers only arises if standard borrowers misbehave when choosing $\left(B_{11}^{S 1 * *}\right.$, $\left.B_{11}^{F 1 * *}, I_{11}^{1 * *}\right){ }^{18}$

We characterize contract $\left(B_{11}^{S 1 * *}, B_{11}^{F 1 * *}, I_{11}^{1 * *}\right)$ in the following lemma.

Lemma 7 If $\Delta_{\theta} \geq \bar{\Delta}_{\theta}$, in the optimal separating contract with no cross subsidization standard borrowers obtain the second-best debt contract. Motivated borrowers obtain a debt contract with lower revenue and investment than their second-best contract, but higher investment, than the second best contract offered to standard borrowers.

Proof. See the Appendix A.6.

When $\Delta_{\theta} \geq \bar{\Delta}_{\theta}$, the equilibrium contracts described in the previous Lemma imply that the "better" type pay the cost of separation from the "worst" agents

\footnotetext{
${ }^{18}$ In Appendix A.5 we show that the solution to program (21) with self-selection constraint (22) dominates the solution of an alternative program we could consider here; that is a program where a pooling contract is offered to both types of borrowers and where the incentive compatibility constraint also hold for standard borrowers.
} 
by receiving a distorted allocation. These contracts share this property with the Rothschild and Stiglitz (1976) ones, although they are obtained in different setups.

Notice that the separating contracts described in the previous lemma assure that motivated borrowers trade with ethical banks whereas standard ones trade with standard banks. Thus, in the third-best, the credit market is fully segmented not only when $\widetilde{\Delta}_{\theta}(\theta) \leq \Delta_{\theta} \leq \bar{\Delta}_{\theta}$, as we established before, but also when $\Delta_{\theta} \geq \bar{\Delta}_{\theta}$.

The following proposition summarizes all results in this section:

\section{Proposition 2 Moral hazard and adverse selection on the borrowers' side: optimal separating contracts with no cross subsidy.}

- When $\Delta_{\theta} \geq \bar{\Delta}_{\theta}$, standard borrowers sign the second-best contract $\left(B_{00}^{S 0 *}\right.$, $\left.B_{00}^{F 0 *}, I_{00}^{0 *}\right)$ with standard lenders. Motivated borrowers sign a debt contract $\left(B_{11}^{S 1 * *}, B_{11}^{F 1 * *}, I_{11}^{1 * *}\right)$ with ethical banks such that $B_{11}^{S 1 * *}<B_{00}^{S 0 *}, I_{11}^{1 * *}>$ $I_{00}^{0 *}$ and $B_{11}^{S 1 * *}<B_{11}^{S 1 *}, I_{11}^{1 * *}<I_{11}^{1 *}$. The credit market is fully segmented.

- When $\widetilde{\Delta}_{\theta}(\theta) \leq \Delta_{\theta} \leq \bar{\Delta}_{\theta}$, the second-best contracts $\left(B_{00}^{S 0 *}, B_{00}^{F 0 *}, I_{00}^{0 *}\right)$ and $\left(B_{11}^{S 1 *}, B_{11}^{\bar{F} 1 *}, I_{11}^{1 *}\right)$ are envy free and are also offered in third-best. The credit market is fully segmented.

- When $\Delta_{\theta}<\widetilde{\Delta}_{\theta}(\theta)$ then both borrowers' types obtain the second-best contract $\left(B_{0 j}^{S 0 *}, B_{0 j}^{F 0 *}, I_{0 j}^{0 *}\right)$. Ethical banks are not active and the market for ethical projects does not exist.

Recall that, when $\Delta_{\theta} \geq \bar{\Delta}_{\theta}$, the premium for successful interaction more than compensates ethical projects low profitability and, in second-best, motivated borrowers receive a more profitable contract. Thus, in third-best, standard borrowers are willing to mimic motivated ones and a self-selecting contract is offered to motivated entrepreneurs who are worse off with respect to the second-best. In particular, motivated borrowers obtain a contract that is characterized by a higher investment but a lower expected revenue with respect to standard borrowers, exactly as it occurs in the second-best for value of $\theta$ such that $\Delta_{\theta} \leq \Delta_{\theta} \leq \bar{\Delta}_{\theta}$ (see Proposition 1). When, instead, the premium for social responsibility is characterized by an intermediate size $\left(\widetilde{\Delta}_{\theta}(\theta) \leq \Delta_{\theta}\right.$ $\leq \bar{\Delta}_{\theta}$ ), adverse selection has no bite so that contracts designed for motivated borrowers in second-best are not attractive for standard ones. Finally, when standard projects profitability more than compensate the total premium for social responsibility $\left(\Delta_{\theta}<\widetilde{\Delta}_{\theta}(\theta)\right)$ all borrowers become equivalent to standard entrepreneurs and no adverse selection issues arise.

Exactly as in the second-best, for $\Delta_{\theta} \geq \widetilde{\Delta}_{\theta}(\theta)$ the market is fully segmented whereas, for $\Delta_{\theta}<\widetilde{\Delta}_{\theta}(\theta)$, the market for ethical projects does not exist since all borrowers invest in standard projects. The important difference with respect to the second-best is in the distortion that characterizes the third-best contract for motivated borrowers when $\Delta_{\theta} \geq \bar{\Delta}_{\theta}$. Such a distortion is necessary to separate borrowers' types and obviously decreases the efficiency arising in second-best 
from assortative matching between agents characterized by sensitivity to social issues.

The previous results are summarized in Figure 2 below. The third-best contracts are compared and the market segmentation is illustrated as a function of the premium for successful interaction $\Delta_{\theta}$.

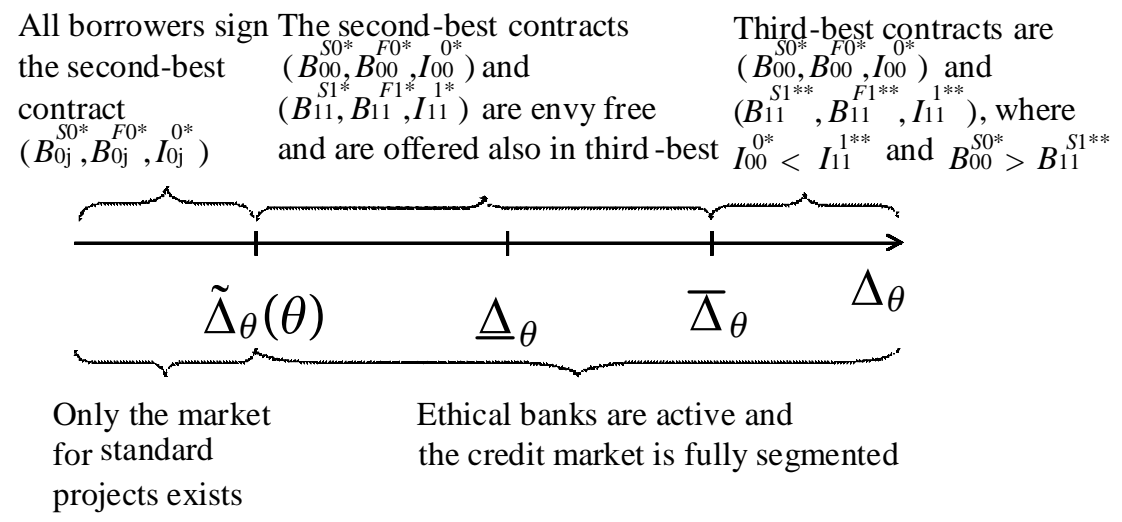

Figure 2. Moral hazard and screening (third-best): given the relative expected returns of standard and ethical projects, third-best contracts depend on the magnitude of the premium for successful interaction as illustrated in

Proposition 2

$\bar{\Delta}_{\theta}$ We now consider conditions assuring the existence and efficiency of the third best equilibrium when $\Delta_{\theta} \geq \bar{\Delta}_{\theta}$.

In order to prove the existence of the equilibrium with contracts $\left(B_{11}^{S 1 * *}\right.$, $\left.B_{11}^{F 1 * *}, I_{11}^{1 * *}\right)$ for motivated borrowers and $\left(B_{0 j}^{S 0 *}, B_{0 j}^{F 0 *}, I_{0 j}^{0 *}\right)$ for standard ones derived in Lemma 7 when $\Delta_{\theta} \geq \bar{\Delta}_{\theta}$, we have to verify that the allocation is robust to the fact that we remove the restriction of no cross-subsidy between borrowers. That is, we have to prove that there is no profitable deviation characterized either by a pooling contract or by separating contracts with crosssubsidizations between the two types of borrowers. In fact, in principle, ethical banks could find it profitable to increase the expected profit of the standard borrower in order to lower the distortions of the ethical borrower's contract.

Interestingly, we will show that, when the third-best equilibrium is efficient, then existence is assured. We then turn to efficiency. In our setting, the optimal self-selecting allocation offered by ethical banks and without cross-subsidy between borrowers types would be the couple of contracts $\left(B_{11}^{S 1 * *}, B_{11}^{F 1 * *}, I_{11}^{1 * *}\right)$ for motivated borrowers and $\left(B_{10}^{S 1 *}, B_{10}^{F 1 *}, I_{10}^{1 *}\right)$ for standard ones. Since, in the incentive compatible constraint $(22)$, we replaced the contract offered by ethical banks to standard borrowers $\left(B_{10}^{S 1 *}, B_{10}^{F 1 *}, I_{10}^{1 *}\right)$ with the dominant contract $\left(B_{0 j}^{S 0 *}, B_{0 j}^{F 0 *}, I_{0 j}^{0 *}\right)$ offered by standard lenders (thus decreasing the distortion necessary for separation), the contract characterizes in Lemma 7 is already more 
efficient than that previously mentioned. ${ }^{19}$ However we can prove a stronger result about efficiency with quite weak assumptions. In fact, we can prove that the third-best contract derived in Lemma 7 is Pareto efficient, provided that $q$ is lower than $\frac{1}{2}$. That is, under this condition, there is no cross-subsidizing scheme among banks which can sustain a better set of contracts. Moreover, if the allocation derived in Lemma 7 is constrained efficient, all the third-best contracts described in Proposition 2 are constrained efficient too, whatever the value of $\Delta_{\theta}$.

The proof of Proposition 3 is built as follows. As mentioned before, the self-selecting equilibrium derived in Lemma 7 is constrained efficient if an (alternative) pair of Pareto dominating contracts with cross-subsidies between ethical and standard banks does not exist. In order to check this, in a first step, we characterize the profit maximizing (loss minimizing) contract for a standard bank when providing an expected profit to the standard borrower which is equal to the second best profits plus $R$. This $R$ is the transfer that has to be paid by ethical banks to standard ones. Cross subsidization between different types of banks is possible if ethical banks make positive profits on an alternative contract $\left(B_{11}^{S 1}, B_{11}^{F 1}, I_{11}^{1}\right)$ that motivated borrowers prefer to $\left(B_{11}^{S 1 * *}, B_{11}^{F 1 * *}, I_{11}^{1 * *}\right)$. Thus, in the second step, we verify whether a Pareto improving new contract $\left(B_{11}^{S 1}, B_{11}^{F 1}, I_{11}^{1}\right)$ can be offered to motivated borrowers by ethical banks that also allow to pay the transfer $R$ to standard lenders. We show that for $q<\frac{1}{2}$ this is not possible and hence no Pareto improving contracts with cross-subsidy between types of banks exists.

Proposition 3 Moral hazard and adverse selection on the borrowers' side: efficiency. $q<\frac{1}{2}$ is a sufficient condition such that the equilibrium of third-best with no cross-subsidization between banks is constrained efficient. However, larger values of $q$ are still compatible with efficiency.

Proof. See Appendix A.7.

An important implication of the previous Proposition is that the third-best equilibrium always exists for $q<\frac{1}{2}$. In fact, we just proved that no profitable deviations with cross-subsidies between the two types of banks exist when $q<\frac{1}{2}$ in an equilibrium with assortative matching. Thus, we can conclude that neither profitable deviations with cross-subsidization between the two types of borrowers exist when $q<\frac{1}{2}$. Or, the separating equilibrium derived in Lemma 7 for $\Delta_{\theta} \geq \bar{\Delta}_{\theta}$ always exists when $q<\frac{1}{2}$.

Corollary 1 Moral hazard and adverse selection on the borrowers' side: existence. $q<\frac{1}{2}$ is a sufficient condition such that the equilibrium of third-best exists. However, larger values of $q$ are still compatible with existence.

Thus, if we do not expect that motivated borrowers represent a majority in the population of investors, the third-best equilibrium described in Proposition 2 exists and it is efficient. ${ }^{20}$

\footnotetext{
${ }^{19}$ Thus, our third-best equilibrium allocation is a particular and more efficient version of the "low-information-intensity optimum" defined in Tirole (2006, page 264).

${ }^{20}$ Suppose, on the contrary, that $q$ is so large that our third-best equilibrium is not efficient.
} 


\section{Conclusion}

Our paper investigates corporate finance of ethical banks. To the best of our knowledge this analysis was still missing in the credit markets literature.

In our model two different credit markets exist: the market for standard projects and the market for ethical ones. We define ethical projects as projects with both social and economic profitability but a lower expected revenue with respect to standard ones. We model ethical banks as lenders which are able to commit to financing only ethical projects so that they are not interested in operating in the markets for standard projects. Motivated borrowers, instead, obtain a general benefit (a premium for social responsibility) when they undertake ethical projects and also an additional benefit from trading with ethical banks in the case their project is successful. This implies that motivated borrowers prefer to trade with ethical banks as long as the contract conditions are not too unfavorable with respect to those offered by standard lenders. Under different information structures, we investigate how ethical banks and motivated borrowers interact together when credit markets are competitive and also standard banks and borrowers are active. First we analyze the case where banks do not observe borrowers' behavior (the pure moral hazard case). We then investigate the case where banks do not observe neither borrowers' behavior nor borrowers' motivation (the case of moral hazard and adverse selection on the borrowers' side). We show that all optimal contracts are debt ones and we fully characterize them in the two information structures.

In equilibrium, standard borrowers always prefer to invest in the market for standard projects, whereas motivated borrowers invest in ethical projects if the additional premium for successful interaction is high enough. In such a case, only standard agents operate in the market for standard projects and only agents aware of social issues trade in the market for ethical projects, implying that the market is fully segmented. Moreover, if the premium for successful interaction is even higher, motivated borrowers prefer to invest in ethical projects and the premium for successful interaction more than compensate the lower profitability of ethical projects. This implies that, ethical banks induce repayment of their loan at a lower cost by providing funds to motivated borrowers. In different words, ethical banks improve market efficiency since they solve more efficiently the moral hazard problem.

In our model, optimal contracts require the same collateral for all borrowers, while they specify different amounts of investment for different borrowers. We could alternatively assume a fixed investment for all the borrowers/projects that would lead to a different collateral for different borrowers. In this alternative

In such a case the government should intervene to allow for a cross subsidy between banks. In particular, ethical banks should pay a transfer to standard banks so that standard borrowers can receive a contract which strictly dominates $\left(B_{00}^{S 0 *}, B_{00}^{F 0 *}, I_{00}^{0 *}\right)$; hence, the self-selection constraint (22) in the third-best program can be relaxed and a contract that is better than $\left(B_{11}^{S 1 * *}, B_{11}^{F 1 * *}, I_{11}^{1 * *}\right)$ can be offered to motivated borrowers (see the proof of Proposition 3 for more details). Note that the credit market would be fully segmented also under this scenario; however, here the financial activity of ethical banks would partially subsidize standard lenders and the market for standard projects. 
case and for values of the premium for successful interaction sufficiently high, our model would predict that motivated borrowers would be asked to provide a lower collateral with respect to standard borrowers. In different words, motivated borrowers would have to pay what we can call an "ethical collateral".

In line with Bénabou and Tirole's view of CSR, our model interprets ethical banks as firms correcting some market failures in the credit market. In particular, in equilibrium, standard lenders are only active in the market for standard projects so that, without ethical banks, the market for ethical projects would never exist. Thus, our results suggest that, in the real world, ethical banks can be welfare improving not only because they can solve more efficiently the moral hazard problem when interacting with motivated borrowers, but also because they allow the financing of projects exerting a positive externality to the society.

\section{References}

[1] Baron, D. (2001), "Private Politics, Corporate Social Responsibility and Integrated Strategy", Journal of Economics and Management Strategy, 10:7-45.

[2] Bénabou R. and J. Tirole (2010), "Individual and Corporate Social Responsibility", Economica 77, 1-19.

[3] Besley T. and S. Coate (1995), "Group Lending, Repayment Incentives and Social Collateral", Journal of Development Economics 46(95), 1-18.

[4] Besley T. and M. Ghatak (2005), "Competition and Incentives with Motivated Agents", The American Economic Review 95(3), 616-636.

[5] Besley T. and M. Ghatak (2007), "Retailing Public Goods: The Economics of Corporate Social Responsibility", Journal of Public Economics 91, 1645-1663.

[6] Blinder A. (1993), "A Simple Note on the Japanese Firms", Journal of the Japanese and International Economies 7, 238-255.

[7] Commission of the European Communities (2001), Green paper "Promoting a European framework for Corporate Social Responsibility", Brussel 18.7.2001 $\operatorname{COM}(2001) 366$ final.

[8] Ghatak M. (1999), "Group Lending, Local Information and Peer Selection", Journal of Development Economics, 60(1),

[9] Green C.F. (1989) "Business Ethics in Banking", Journal of Business Ethics, 8(8), 631-34.

[10] Jensen M. and W. H. Meckling (1976), "Theory of the Firm: Managerial Behavior, Agency Costs and Ownership Structure", Journal of Financial Economics 3 (4): 305-360.

[11] Kosfeld, M. and F.A. von Siemens (2009), "Worker Self-Selection and the Profits from Cooperation", Journal of the European Economic Association, 7(2-3), 573-582. 
[12] Leland, H. and Pyle, H. (1977), "Informational Asymmetries, Financial Structure, and Financial Intermediation," Journal of Finance, 32(2), 371-387.

[13] Lynch J.J. (1991), Ethical Bank: Surviving in an Age of Default, London McMillan.

[14] Maskin E. and J. Tirole (1992), "The Principal-Agent Relationship with an Informed Principal, II: Common Values", Econometrica, vol. 60(1), $1-42$.

[15] Rabin (1993), "Incorporating Fairness into Game Theory and Economics," American Economic Review vol. 83(5), 1281-1302.

[16] Rothschild, M. and J. Stiglitz (1976), "Equilibrium in Insurance Markets: an essay on the economics of imperfect information", Quarterly Journal of Economics 90, pp. 629-649.

[17] San José L., J.L. Retolaza and J. Gutierrez (2009), "Are Ethical Banks Different? A Comparative Analysis Using the Radical Affinity Index", Journal of Business Ethics, vol. 100(1), 151-173.

[18] Stiglitz J.E. (1990), "Peer Monitoring and Credit Markets", The World Bank Economic Review 4(3), 351-366.

[19] Tirole J. (2006), The theory of Corporate Finance, Princeton and Oxford: Princeton University Press.

[20] Social Investment Forum (2007) Report on Socially Responsible Investing Trends in the U.S., Available at http://www.socialinvest.org/resources/research/

[21] Waring, Geoffrey F. (1996), "Industry Differences in the Persistence of Firm-Specific Returns", American Economic Review(86), 1253-1265.

\section{A Appendix}

\section{A.1 Proof of Lemma 2}

The following proof is quite standard (see Tirole 2006), however we prefer to insert it since it turns out to be useful to understanding results in Section 3. Remember that we are solving a program that is equivalent to Program 9.

It is easy to prove that $\left(I R_{0 j}^{L 0}\right)$ must be satisfied with equality. In fact, if we assume the opposite, the borrower can add a small and equal amount both to $B_{0 j}^{S 0}$ and $B_{0 j}^{F 0}$ leaving $\left(I C_{0 j}^{B 0}\right)$ satisfied, but increasing the expected utility. Hence we have a contradiction.

Notice that, since $\left(I R_{0 j}^{L 0}\right)$ is binding :

$$
p_{H}\left(B_{0 j}^{S 0}-B_{0 j}^{F 0}\right)+B_{0 j}^{F 0}-A=p_{H}\left(R^{S 0}-R^{F}\right) I_{0 j}^{0}+R^{F} I_{0 j}^{0}-I_{0 j}^{0}
$$

and substituting the previous expression in the objective function, it yields:

$$
\max \left(p_{H} \Delta_{R_{0}}+R^{F}-1\right) I_{0 j}^{0}
$$


which implies that the borrower wishes to increase the investment, $I_{0 j}^{0}$, as much as he can. However, according to expression (11), $I_{0 j}^{0}$ must be finite. Thus, to assure that the highest as possible value of $I_{0 j}^{0}$ is reached, also $\left(I C_{0 j}^{B 0}\right)$ has to be binding.

Now suppose that $B_{0 j}^{F 0}>0$. Hence we can clearly decrease it by a small amount $\partial B_{0 j}^{F 0}$ and increase $B_{0 j}^{S 0}$ by another small amount $\partial B_{0 j}^{S 0}$ in such a way that:

$$
p_{H} \partial B_{0 j}^{S 0}+\left(1-p_{H}\right) \partial B_{0 j}^{F 0}=0
$$

In this case $\left(I R_{0 j}^{L 0}\right)$ is still satisfied, $U_{j}^{0}$ is unchanged but, since $B_{0 j}^{S 0}$ increases while $B_{0 j}^{F 0}$ decreases, $\left(I C_{0 j}^{B 0}\right)$ is now slack, a contradiction. Hence

$$
B_{0 j}^{F 0 *}=0
$$

the lender offers a debt contract to the borrower, with the value of the debt $D$, satisfying $D>R^{F} I_{0 j}^{0}$. Substituting the above result in (11) and recalling that this last inequality is satisfied with equality if $\left(I C_{0 j}^{B 0}\right)$ and $\left(I R_{0 j}^{L 0}\right)$ are, we obtain:

$$
I_{0 j}^{0 *}=\frac{A}{1-\left[p_{H}\left(\Delta_{R_{0}}-\frac{P}{\Delta_{p}}\right)+R^{F}\right]}
$$

Finally, substituting in $\left(I C_{0 j}^{B 0}\right)$ we obtain the equilibrium revenues of the borrower in the good state.

\section{A.2 Proof of Lemma 3}

As before $\left(I R_{11}^{L 1}\right)$ should be satisfied with equality and substituting it in the objective function this implies that the borrower wishes to set $I_{11}^{1}$ as large as possible. If we can prove that $\left(I C_{11}^{B 1}\right)$ implies finite $I_{11}^{1}$, the proof can follow the same lines as in the previous case. Using $\left(I C_{11}^{B 1}\right)$ in $\left(I R_{11}^{L 1}\right)$ we obtain:

$$
I_{11}^{1} \leq \frac{A-B_{11}^{F 1}+\Delta_{\theta} p_{H}}{1-p_{H}\left(\Delta_{R_{1}}-\frac{P}{\Delta_{p}}\right)-R^{F}}
$$

The denominator of the rhs is positive because of (10). Hence $I_{11}^{1}$ has to be finite. Since the borrower wishes to set $I_{11}^{1}$ as large as possible, $\left(I C_{11}^{B 1}\right)$ cannot be slack.

Now suppose that $B_{11}^{F 1}>0$. We can reach a contradiction according to the same lines of the profit maximizing borrower. Hence $B_{11}^{F 1}=0$ : again we have a debt contract. Substituting $B_{11}^{F 1}=0$ in (24) and in $\left(I C_{11}^{B 1}\right)$, where (24) is taken with equality since both $\left(I C_{11}^{B 1}\right)$ and $\left(I R_{11}^{L 1}\right)$ are taken with equality, we 
obtain:

$$
\begin{aligned}
B_{11}^{S 1 *}= & \frac{\frac{P}{\Delta_{p}} A}{1-p_{H}\left(\Delta_{R_{1}}-\frac{P}{\Delta_{p}}\right)-R^{F}}+\frac{p_{H} \Delta_{R_{1}}+R^{F}-1}{1-p_{H}\left(\Delta_{R_{1}}-\frac{P}{\Delta_{p}}\right)-R^{F}} \Delta_{\theta}= \\
& B_{0 j}^{S 1 *}+\frac{p_{H} \Delta_{R_{1}}+R^{F}-1}{1-p_{H}\left(\Delta_{R_{1}}-\frac{P}{\Delta_{p}}\right)-R^{F}} \Delta_{\theta}
\end{aligned}
$$

\section{A.3 Proof of Lemma 4}

The inequality $I_{11}^{1 *} \geq I_{0 j}^{0 *}$ holds if and only if:

$$
\frac{A+p_{H} \Delta_{\theta}}{1-p_{H}\left(\Delta_{R_{1}}-\frac{P}{\Delta_{p}}\right)-R^{F}} \geq \frac{A}{1-p_{H}\left(\Delta_{R_{0}}-\frac{P}{\Delta_{p}}\right)-R^{F}}
$$

that is:

$$
\Delta_{\theta} \geq \frac{A\left(\Delta_{R_{0}}-\Delta_{R_{1}}\right)}{1-p_{H}\left(\Delta_{R_{0}}-\frac{P}{\Delta_{p}}\right)-R^{F}}=I_{0 j}^{0 *}\left(\Delta_{R_{0}}-\Delta_{R_{1}}\right)
$$

The socially responsible entrepreneur trading with an ethical bank pays less if: $B_{11}^{S 1 *}>B_{0 j}^{S 0 *}$, that is:

$$
\frac{P}{\Delta_{p}} \frac{A+p_{H} \Delta_{\theta}}{1-p_{H}\left(\Delta_{R_{1}}-\frac{P}{\Delta_{p}}\right)-R^{F}}-\Delta_{\theta} \geq \frac{P}{\Delta_{p}} \frac{A}{1-p_{H}\left(\Delta_{R_{0}}-\frac{P}{\Delta_{p}}\right)-R^{F}}
$$

or:

$$
\begin{gathered}
\frac{\Delta_{\theta}\left(p_{H} \Delta_{R_{1}}+R^{F}-1\right)}{1-p_{H}\left(\Delta_{R_{1}}-\frac{P}{\Delta_{p}}\right)-R^{F}} \geq \\
\frac{P A}{\Delta_{p}} \frac{p_{H}\left(\Delta_{R_{0}}-\Delta_{R_{1}}\right)}{\left(1-p_{H}\left(\Delta_{R_{1}}-\frac{P}{\Delta_{p}}\right)-R^{F}\right)\left(1-p_{H}\left(\Delta_{R_{0}}-\frac{P}{\Delta_{p}}\right)-R^{F}\right)}
\end{gathered}
$$

and finally:

$$
\Delta_{\theta}\left(p_{H} \Delta_{R_{1}}+R^{F}-1\right) \geq \frac{P}{\Delta_{p}} p_{H}\left(\Delta_{R_{0}}-\Delta_{R_{1}}\right) I_{0 j}^{0 *}
$$

which is equivalent to (19). It is easy to prove that

$$
\frac{p_{H} P}{\Delta_{p}\left(p_{H} \Delta_{R_{1}}+R^{F}-1\right)}>1
$$

and hence (19) implies (18). 


\section{A.4 Proof of Lemma 5}

Motivated borrowers prefer to trade with socially responsible lenders if, by doing so, they receive a higher expected utility than the one they would receive with standard lenders:

$$
p_{H} \Delta_{B_{11}^{1 *}}+p_{H} \Delta_{\theta}+\theta+B_{11}^{F 1 *}-A \geq p_{H} \Delta_{B_{0 j}^{0 *}}+B_{0 j}^{F 0 *}-A
$$

which implies:

$$
p_{H} \Delta_{\theta}+\theta \geq p_{H}\left(\Delta_{B_{0 j}^{0 *}}-\Delta_{B_{11}^{1 *}}\right)=p_{H}\left(B_{0 j}^{S 0 *}-B_{11}^{S 1 *}\right)
$$

By substituting $B_{0 j}^{S 0 *}$ and $B_{11}^{S 1 *}$ as from Lemma 2 and Lemma 3 we find:

$p_{H} \Delta_{\theta}+\theta \geq p_{H} \frac{P}{\Delta_{p}} \frac{A}{1-p_{H}\left(\Delta_{R_{0}}-\frac{P}{\Delta_{p}}\right)-R^{F}}-p_{H}\left(\frac{P}{\Delta_{p}} \frac{A+p_{H} \Delta_{\theta}}{1-p_{H}\left(\Delta_{R_{1}}-\frac{P}{\Delta_{p}}\right)-R^{F}}-\Delta_{\theta}\right)$

Rearranging:

$$
\frac{\theta}{p_{H}^{2}} \frac{\Delta_{p}}{P}\left(1-p_{H}\left(\Delta_{R_{1}}-\frac{P}{\Delta_{p}}\right)-R^{F}\right)+\Delta_{\theta} \geq I_{0 j}^{0 *}\left(\Delta_{R_{0}}-\Delta_{R_{1}}\right)=\underline{\Delta}_{\theta}
$$

where $\frac{\theta}{p_{H}^{2}} \frac{\Delta_{p}}{P}\left(1-p_{H}\left(\Delta_{R_{1}}-\frac{P}{\Delta_{p}}\right)-R^{F}\right)>0$.

Thus, motivated borrowers prefer to trade with ethical banks if:

$$
\Delta_{\theta} \geq \underline{\Delta}_{\theta}-\frac{\theta}{p_{H}^{2}} \frac{\Delta_{p}}{P}\left(1-p_{H}\left(\Delta_{R_{1}}-\frac{P}{\Delta_{p}}\right)-R^{F}\right)=\widetilde{\Delta}_{\theta}(\theta)<\underline{\Delta}_{\theta}
$$

Note that, if $\theta=0$, then it must be:

$$
\Delta_{\theta} \geq \underline{\Delta}_{\theta}=\frac{A\left(\Delta_{R_{0}}-\Delta_{R_{1}}\right)}{1-p_{H}\left(\Delta_{R_{0}}-\frac{P}{\Delta_{p}}\right)-R^{F}}
$$

We now derive the value of $\theta$ such that $\widetilde{\Delta}_{\theta}(\theta)>0$. Substituting the value for $\Delta_{\theta}$ in the previous expression:

$$
\widetilde{\Delta}_{\theta}(\theta)=I_{0 j}^{0 *}\left(\Delta_{R_{0}}-\Delta_{R_{1}}\right)-\theta \frac{\Delta_{p}}{p_{H}^{2} P}\left(1-p_{H}\left(\Delta_{R_{1}}-\frac{P}{\Delta_{p}}\right)-R^{F}\right)>0
$$

Solving for $\theta$ we find that $\widetilde{\Delta}_{\theta}(\theta)>0$ when:

$$
\theta<\frac{p_{H}^{2} P\left(\Delta_{R_{0}}-\Delta_{R_{1}}\right) A}{\Delta_{p}\left(1-p_{H}\left(\Delta_{R_{0}}-\frac{P}{\Delta_{p}}\right)-R^{F}\right)\left(1-p_{H}\left(\Delta_{R_{1}}-\frac{P}{\Delta_{p}}\right)-R^{F}\right)}
$$




\section{A.5 Ethical banks offer a pooling contract in third-best}

An alternative possibility would be to consider a different program with no selfselection constraint and where the incentive compatibility constraint $\left(I C_{1 j}^{B 1}\right)$ instead of $\left(I C_{11}^{B 1}\right)$ must be met, or $\Delta_{B_{1 j}^{1}} \geq \frac{P}{\Delta_{p}} I_{1 j}^{1}$. In fact, when $\left(I C_{1 j}^{B 1}\right)$ is verified, a forthiori also $\left(I C_{11}^{B 1}\right)$ holds. In this case ethical banks would offer a pooling contract $\left(B_{1 j}^{S 1 * *}, B_{1 j}^{F 1 * *}, I_{1 j}^{1 * *}\right)$ that is potentially signed by both borrowers' types and the program to be solved would be the following:

$$
\begin{array}{ccc}
\max _{\Delta_{B_{1 j}^{1}}^{1}, B_{1 j}^{F 1}, I_{1 j}^{1}} & p_{H} \Delta_{B_{1 j}^{1}}+p_{H} \Delta_{\theta}+\theta+B_{1 j}^{F 1}-A & \\
\text { s.t. } & \Delta_{B_{1 j}^{1}} \geq \frac{P}{\Delta_{p}} I_{1 j}^{1} & \left(I C_{1 j}^{B 1}\right) \\
& \left(p_{H} \Delta_{R_{1}}+R^{F}-1\right) I_{1 j}^{1} & \left(I R_{1 j}^{L 1}\right) \\
& -p_{H} \Delta_{B_{1 j}^{1}}-B_{1 j}^{F 1}+A \geq 0 &
\end{array}
$$

However the two constraints in (25) are the same that must be considered in order to obtain the optimal second-best contract $\left(B_{i 0}^{S 1 *}, B_{i 0}^{F 1 *}, I_{i 0}^{1 *}\right)$ that both types of lenders offer to standard borrowers undertaking ethical projects (see Subsection 3.1.2). Moreover, the premia $p_{H} \Delta_{\theta}+\theta$ for social responsibility appearing in the objective function of (25) do not affect the optimal contract. Thus, we observe that the solution of program (25) must be equivalent to $\left(B_{i 0}^{S 1 *}, B_{i 0}^{F 1 *}, I_{i 0}^{1 *}\right)$, that is to the contract that is not chosen neither by standard nor by motivated borrowers at the second-best equilibrium. As a consequence, we can conclude that the more efficient allocation is the one derived by program (21). All the previous reasoning allows us to conclude that the program to be considered in the third-best is (21) with self-selection constraint (22).

\section{A.6 Proof of Lemma 7}

Remember that the relevant self-selection constraint is the one where the standard borrower misbehaves. In fact, if the mimicker behaves, then the ethical bank has no reason to avoid the standard borrower signing the contract designed for the ethical one. Moreover we relax the self-selection constraint by considering expected profits the borrower obtains when trading with a standard bank in second-best. Therefore, the problem to be solved is the following:

$$
\begin{array}{ccc}
\max _{\Delta_{B_{11}^{1}}, B_{11}^{F 1}, I_{11}^{1}} & p_{H} \Delta_{B_{11}^{1}}+p_{H} \Delta_{\theta}+\theta+B_{11}^{F 1}-A \\
\text { s.t. } & \Delta_{B_{11}^{1}}+\Delta_{\theta} \geq \frac{P}{\Delta_{p}} I_{11}^{1} & \left(I C_{11}^{B 1}\right) \\
& \left(p_{H} \Delta_{R_{1}}+R^{F}-1\right) I_{11}^{1}-p_{H} \Delta_{B_{11}^{1}}-B_{11}^{F 1}+A \geq 0 & \left(I R_{11}^{L 1}\right) \\
& p_{H} B_{0 j}^{S 0 *} \geq p_{L} \Delta_{B_{11}^{1}}+B_{11}^{F 1}+P I_{11}^{1} & \left(S S_{1}^{B 1}\right)
\end{array}
$$

Notice that in this program $\left(S S_{1}^{B 1}\right)$ must be binding, otherwise parties could reach the second-best program which is not feasible by assumption, because 
in the second-best contracts the profit maximizer borrower would prefer the motivated borrower's contract. Hence

$$
p_{H} B_{0 j}^{S 0 *}=p_{L} \Delta_{B_{11}^{1}}+B_{11}^{F 1}+P I_{11}^{1}
$$

That is:

$$
p_{H} \Delta_{B_{11}^{1}}+B_{11}^{F 1}=p_{H} B_{0 j}^{S 0 *}+\Delta_{p} \Delta_{B_{11}^{1}}-P I_{11}^{1}
$$

Let us make the working assumption that the optimal contract is a debt contract, that is: $B_{11}^{F 1}=0$. We first characterize the optimal debt contract. Then we prove that no other contract can do better than the optimal debt one. Notice that the three constraints in Program 26 can be written as:

$$
\begin{array}{cc}
I_{11}^{1} \leq \frac{\Delta_{p}}{P} \Delta_{B_{11}^{1}}+\frac{\Delta_{p}}{P} \Delta_{\theta} & \left(I C_{11}^{B 1}\right) \\
I_{11}^{1} \geq \frac{p_{H} \Delta_{B_{11}^{1}}-A}{\left(p_{H} \Delta_{R_{1}}+R^{F}-1\right)} & \left(I R_{11}^{L 1}\right) \\
I_{11}^{1} \leq \frac{p_{H}}{P} B_{0 j}^{S 0 *}-\frac{p_{L}}{P} \Delta_{B_{11}^{1}} & \left(S S_{1}^{B 1}\right)
\end{array}
$$

In the space $\left(\Delta_{B_{11}^{1}}, I_{11}^{1}\right)$ the boundary of the sets are straight lines. That of $\left(S S_{1}^{B 1}\right)$ is negatively sloped while those of the other two are positively sloped. Suppose now that $\left(I C_{11}^{B 1}\right)$ is binding and hence holds with equality. Then substituting $\left(I C_{11}^{B 1}\right)$ into $\left(S S_{1}^{B 1}\right)$ (which is binding) we obtain:

$p_{H} B_{0 j}^{S 0 *}=p_{L}\left(\frac{P}{\Delta_{p}} I_{11}^{1}-\Delta_{\theta}\right)+P I_{11}^{1}=\left(\frac{p_{L}}{\Delta_{p}}+1\right) P I_{11}^{1}-p_{L} \Delta_{\theta}=\frac{p_{H}}{\Delta_{p}} P I_{11}^{1}-p_{L} \Delta_{\theta}$

that is:

$$
\begin{gathered}
I_{11}^{1}=\frac{\Delta_{p}}{P} B_{0 j}^{S 0 *}+\frac{\Delta_{p}}{P} \frac{p_{L}}{p_{H}} \Delta_{\theta}= \\
\frac{\Delta_{p}}{P} \frac{P}{\Delta_{p}} \frac{A}{1-p_{H}\left(\Delta_{R_{0}}-\frac{P}{\Delta_{p}}\right)-R^{F}}+\frac{\Delta_{p}}{P} \frac{p_{L}}{p_{H}} \Delta_{\theta}= \\
\frac{A}{1-p_{H}\left(\Delta_{R_{0}}-\frac{P}{\Delta_{p}}\right)-R^{F}}+\frac{\Delta_{p}}{P} \frac{p_{L}}{p_{H}} \Delta_{\theta}
\end{gathered}
$$

and substituting back into $\left(I C_{11}^{B 1}\right)$ we have the motivated borrower income:

$$
\begin{aligned}
\Delta_{B_{11}^{1}} & =\frac{P}{\Delta_{p}}\left(\frac{A}{1-p_{H}\left(\Delta_{R_{0}}-\frac{P}{\Delta_{p}}\right)-R^{F}}+\frac{\Delta_{p}}{P} \frac{p_{L}}{p_{H}} \Delta_{\theta}\right)-\Delta_{\theta} \\
& =\frac{P}{\Delta_{p}} \frac{A}{1-p_{H}\left(\Delta_{R_{0}}-\frac{P}{\Delta_{p}}\right)-R^{F}}-\frac{\Delta_{p}}{p_{H}} \Delta_{\theta}
\end{aligned}
$$


We now check if the participation constraint of the lender is satisfied. If we substitute our result into $\left(I R_{11}^{L}\right)$ we obtain:

$$
\begin{gathered}
\left(p_{H} \Delta_{R_{1}}+R^{F}-1\right) I_{11}^{1}-p_{H} \Delta_{B_{11}^{1}}+A= \\
\left(p_{H} \Delta_{B_{11}^{1}}+R^{F}-1\right)\left(\frac{A}{1-p_{H}\left(\Delta_{R_{0}}-\frac{P}{\Delta_{p}}\right)-R^{F}}+\frac{\Delta_{p}}{P} \frac{p_{L}}{p_{H}} \Delta_{\theta}\right)- \\
p_{H}\left(\frac{P}{\Delta_{p}} \frac{A}{1-p_{H}\left(\Delta_{R_{0}}-\frac{P}{\Delta_{p}}\right)-R^{F}}-\frac{\Delta_{p}}{p_{H}} \Delta_{\theta}\right)+A= \\
-p_{H} \frac{\Delta_{R_{0}}-\Delta_{R_{1}}}{1+\frac{P}{\Delta_{p}} p_{H}-R^{F}-p_{H} \Delta_{R_{0}}} A+\left(p_{H} \Delta_{R_{1}}+R^{F}-1\right) \frac{\Delta_{p}}{P} \frac{p_{L}}{p_{H}} \Delta_{\theta}+\Delta_{p} \Delta_{\theta} \geq 0
\end{gathered}
$$

or:

$$
\left(p_{H} \Delta_{R_{1}}+R^{F}-1\right) \frac{\Delta_{p}}{P} \frac{p_{L}}{p_{H}} \Delta_{\theta}+\Delta_{p} \Delta_{\theta} \geq A p_{H} \frac{\Delta_{R_{0}}-\Delta_{R_{1}}}{1+\frac{P}{\Delta_{p}} p_{H}-R^{F}-p_{H} \Delta_{R_{0}}}
$$

Recall that, from inequality (19), we are considering the following set of parameter values:

$$
\Delta_{\theta} \geq \frac{p_{H} P}{\Delta_{p}} \frac{\left(\Delta_{R_{0}}-\Delta_{R_{1}}\right) I_{0 j}^{0 *}}{p_{H} \Delta_{R_{1}}+R^{F}-1}=\frac{p_{H} P}{\Delta_{p}} \frac{\left(\Delta_{R_{0}}-\Delta_{R_{1}}\right)}{p_{H} \Delta_{R_{1}}+R^{F}-1} \frac{A}{1-p_{H}\left(\Delta_{R_{0}}-\frac{P}{\Delta_{p}}\right)-R^{F}}
$$

Hence the participation constraint is surely satisfied if:

$$
\begin{gathered}
\left(p_{H} \Delta_{R_{1}}+R^{F}-1\right) \frac{\Delta_{p}}{P} \frac{p_{L}}{p_{H}} \frac{p_{H} P}{\Delta_{p}} \frac{\left(\Delta_{R_{0}}-\Delta_{R_{1}}\right)}{p_{H} \Delta_{R_{1}}+R^{F}-1} \frac{A}{1-p_{H}\left(\Delta_{R_{0}}-\frac{P}{\Delta_{p}}\right)-R^{F}}+ \\
p_{H} P \frac{\left(\Delta_{R_{0}}-\Delta_{R_{1}}\right)}{p_{H} \Delta_{R_{1}}+R^{F}-1} \frac{A}{1-p_{H}\left(\Delta_{R_{0}}-\frac{P}{\Delta_{p}}\right)-R^{F}} \geq \\
A p_{H} \frac{\Delta_{R_{0}}-\Delta_{R_{1}}}{1+\frac{P}{\Delta_{p}} p_{H}-R^{F}-p_{H} \Delta_{R_{0}}}
\end{gathered}
$$

which boils down into

$$
\frac{p_{H} P}{p_{H} \Delta_{R_{1}}+R^{F}-1} \geq p_{H}-p_{L}=\Delta_{p}
$$

or

$$
p_{H} \frac{P}{\Delta_{p}}-\left(p_{H} \Delta_{R_{1}}+R^{F}-1\right)=1+\frac{P}{\Delta_{p}} p_{H}-R^{F}-p_{H} \Delta_{R_{1}} \geq 0
$$

which is certainly satisfied for (??). Hence the participation constraint of the lender is satisfied. This implies that the two constraints, $\left(I R_{11}^{L 1}\right)$ and $\left(I C_{11}^{B 1}\right)$, 
are compatible with each other. That is, $\left(I R_{11}^{L 1}\right)$ (taken with equality) crosses $\left(S S_{1}^{B 1}\right)$ at a lower investment level, $I_{11}^{1}$, and (more importantly) at a bigger borrower's revenue, $\Delta_{B_{11}^{1}}$, with respect to $\left(I C_{11}^{B 1}\right)$ (again taken with equality). This means that the former is characterized for the highest $\Delta_{B_{11}^{1}}$, which is also $B_{11}^{S 1}$, since $B_{11}^{F 1}=0$, in the intersection of all constraints. This implies that in the same point the expected utility of the borrower is the highest, as can be checked in the figure, considering that the relevant area is inside the three constraints.

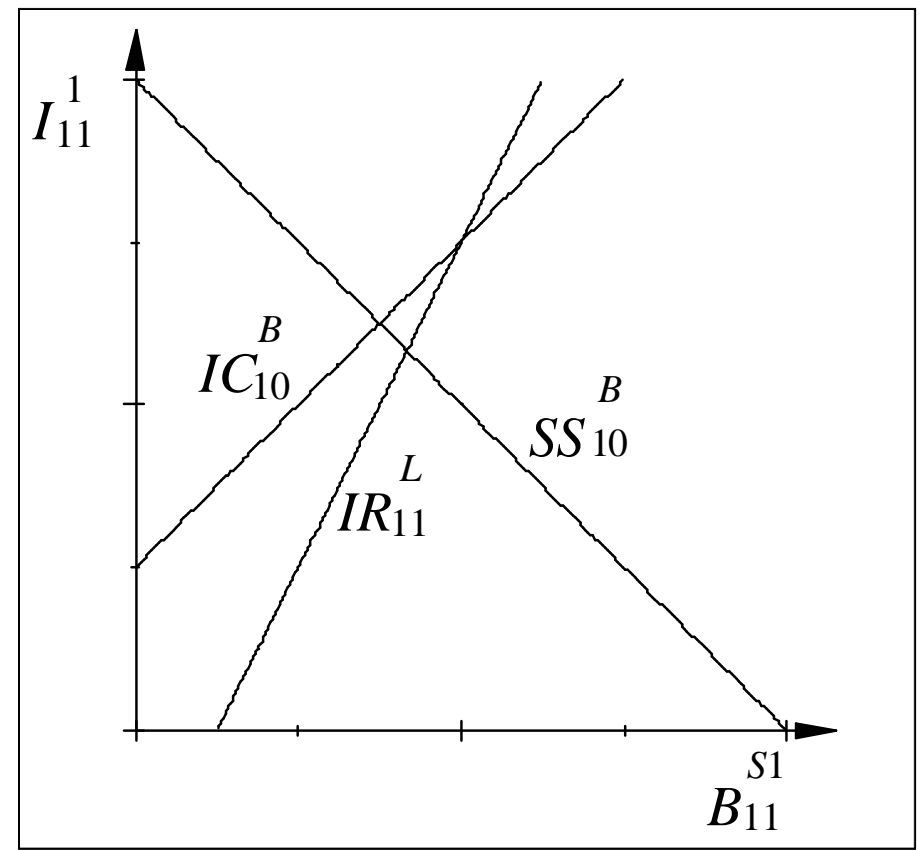

Figure 3: The three constraints in the third-best program

The point where $\left(I R_{11}^{L}\right)$ crosses $\left(S S_{10}^{B}\right)$ is characterized by the system

$$
\left[\begin{array}{cc}
\left(p_{H} \Delta_{R_{1}}+R^{F}-1\right) & -p_{H} \\
P & p_{L}
\end{array}\right]\left[\begin{array}{c}
I_{11}^{1} \\
\Delta_{B_{11}^{1}}^{1}
\end{array}\right]=\left[\begin{array}{c}
-A \\
p_{H} B_{0 j}^{S 0 *}
\end{array}\right]
$$

with solutions:

$$
\begin{aligned}
I_{11}^{1} & =\frac{p_{H}^{2} B_{0 j}^{S 0 *}-p_{L} A}{p_{L}\left(p_{H} \Delta_{R_{1}}+R^{F}-1\right)+p_{H} P} \\
\Delta_{B_{11}^{1}} & =\frac{\left(p_{H} \Delta_{R_{1}}+R^{F}-1\right) p_{H} B_{0 j}^{S 0 *}+A P}{p_{L}\left(p_{H} \Delta_{R_{1}}+R^{F}-1\right)+p_{H} P}
\end{aligned}
$$

This is the optimal debt contract. Now we will prove that this is the best overall contract. Let us take the system $\left(I R_{11}^{L 1}\right)$ and $\left(S S_{1}^{B 1}\right)$ with equality and let us differentiate it with respect to $B_{11}^{F 1}$, we find the following system:

$$
\left[\begin{array}{cc}
\left(p_{H} \Delta_{R_{1}}+R^{F}-1\right) & -p_{H} \\
P & p_{L}
\end{array}\right] d\left[\begin{array}{c}
I_{11}^{1} \\
\Delta_{B_{11}^{1}}^{1}
\end{array}\right]=\left[\begin{array}{c}
1 \\
-1
\end{array}\right] d B_{11}^{F 1}
$$


which implies that:

$$
\frac{\partial \Delta_{B_{11}^{1}}}{\partial B_{11}^{F 1}}=-\frac{P+p_{H} \Delta_{R_{1}}+R^{F}-1}{\left(p_{H} \Delta_{R_{1}}+R^{F}-1\right) p_{L}+P p_{H}}
$$

Hence the expected utility varies with $d B_{11}^{F 1}$ at the rate:

$$
\frac{d}{d R_{b 1}^{F}}\left(p_{H} \Delta_{R_{b 1}}+R_{b 1}^{F}\right)=-\frac{\Delta_{p}\left(p_{H} \Delta_{R_{1}}+R^{F}-1\right)}{\left(p_{H} \Delta_{R_{1}}+R^{F}-1\right) p_{L}+p_{H} P}<0
$$

Hence the best contract when $\left(S S_{1}^{B 1}\right)$ and $\left(I R_{11}^{L 1}\right)$ are binding is just a debt contract, that is with $B_{11}^{F 1}=0$.

If we assume instead that $\left(S S_{1}^{B 1}\right)$ and $\left(I C_{11}^{B 1}\right)$ are binding, we can solve $\left(I C_{11}^{B 1}\right)$ for $I_{11}^{1}$ and obtain:

$$
I_{11}^{1}=\frac{\Delta_{p}}{P} \Delta_{B_{11}^{1}}+\frac{\Delta_{p}}{P} \Delta_{\theta}
$$

and substituting into $\left(S S_{1}^{B 1}\right)$ :

$$
p_{H} \Delta_{B_{11}^{1}}+B_{11}^{F 1}=p_{H} B_{0 j}^{S 0 *}-\Delta_{p} \Delta_{\theta}
$$

Hence the expected utility of the borrower is constant even if we let $B_{11}^{F 1}$ vary. However we already proved that for $B_{11}^{F 1}=0$ the dominating allocation is that where $\left(I R_{11}^{L}\right)$ and $\left(S S_{1}^{B}\right)$ are binding, and that the latter is also the optimal contract. Therefore the best contract for this program is $B_{11}^{F 1}=0$ and:

$$
B_{11}^{S 1 * *}=\frac{\left(p_{H} \Delta_{R_{1}}+R^{F}-1\right) p_{H} B_{0 j}^{S 0 *}+A P}{p_{L}\left(p_{H} \Delta_{R_{1}}+R^{F}-1\right)+p_{H} P}
$$

Substituting the value of $B_{0 j}^{S 0 *}$ we obtain:

$$
\begin{aligned}
B_{11}^{S 1 * *}= & \frac{p_{L}\left(p_{H} \Delta_{R_{1}}+R^{F}-1\right)+p_{H} P-\Delta_{p} p_{H}\left(\Delta_{R_{0}}-\Delta_{R_{1}}\right)}{p_{L}\left(p_{H} \Delta_{R_{1}}+R^{F}-1\right)+p_{H} P} . \\
& \frac{P}{\Delta_{p}} \frac{A}{1-p_{H}\left(\Delta_{R_{0}}-\frac{P}{\Delta_{p}}\right)-R^{F}}
\end{aligned}
$$

while the investment is:

$$
I_{11}^{1 * *}=\frac{p_{H}^{2} B_{0 j}^{S 0 *}-p_{L} A}{p_{L}\left(p_{H} \Delta_{R_{1}}+R^{F}-1\right)+p_{H} P}
$$

and substituting the value of $B_{0 j}^{S 0 *}$ we obtain:

$$
\begin{aligned}
I_{11}^{1 * *}= & \frac{p_{L}\left(p_{H} \Delta_{R_{1}}+R^{F}-1\right)+p_{H} P+p_{L} p_{H}\left(\Delta_{R_{0}}-\Delta_{R_{1}}\right)}{p_{L}\left(p_{H} \Delta_{R_{1}}+R^{F}-1\right)+p_{H} P} . \\
& \frac{A}{1-p_{H}\left(\Delta_{R_{0}}-\frac{P}{\Delta_{p}}\right)-R^{F}}
\end{aligned}
$$


Note that $B_{11}^{S 1 * *}$ and $I_{11}^{1 * *}$ do not depend on $\Delta_{\theta}$ and, by comparison with expressions in Lemma 2, they are such that $B_{11}^{S 1 * *}<B_{0 j}^{S 0 *}$ and $I_{11}^{1 * *}>I_{0 j}^{0 *}$.

Moreover, since when condition (19) holds the contracts are such that $B_{11}^{S 1 *}>$ $B_{0 j}^{S 0 *}$ (see Proposition 1), we have that $B_{11}^{S 1 *}>B_{0 j}^{S 0 *}>B_{11}^{S 1 * *}$. We showed before that the third-best debt contract is at the intersection between $\left(S S_{1}^{B 1}\right)$ and $\left(I R_{11}^{L 1}\right)$. The second-best contract is instead at the intersection between $\left(I C_{11}^{B 1}\right)$ and, again, $\left(I R_{11}^{L 1}\right)$. Moreover, we just proved that $\left(S S_{1}^{B 1}\right)$ crosses $\left(I R_{11}^{L 1}\right)$ at a lower $I_{11}^{1 * *}$ than $\left(I C_{11}^{B 1}\right)$. Since $\left(I R_{11}^{L 1}\right)$ is positively sloped, it must also be true that the level of investment in the third best is lower than in the second best, $I_{11}^{1 * *}<I_{11}^{1 *}$ (see the figure).

\section{A.7 Proof of the Proposition 3}

The self-selecting equilibrium derived in Lemma 7 is constrained efficient if an (alternative) pair of Pareto dominating contracts with cross-subsidies between ethical and standard banks does not exist. Thus, in a first step, we will derive the expected profits of a standard bank when providing a new contract $\left(B_{00}^{S 0}, B_{00}^{F 0}\right.$, $\left.I_{00}^{0}\right)$ to a standard borrower which grants to the latter the second best expected profit plus an additional monetary transfer $R$; then we will check whether this additional transfer $R$ can be paid by an ethical bank as a cross subsidy to the standard one. Cross subsidization between different types of banks is possible if ethical banks make positive profits on an alternative contract $\left(B_{11}^{S 1}, B_{11}^{F 1}, I_{11}^{1}\right)$ that motivated borrowers prefer to $\left(B_{11}^{S 1 * *}, B_{11}^{F 1 * *}, I_{11}^{1 * *}\right)$. Thus, in the second step, we will verify whether a Pareto improving new contract $\left(B_{11}^{S 1}, B_{11}^{F 1}, I_{11}^{1}\right)$ can be offered to motivated borrowers by ethical banks that also allow to pay the transfer $R$ to standard lenders.

First step. In this step we can define the expected profits of a standard bank as a function of $R$. Expected profits are characterized as follows:

$$
\begin{array}{ccc}
\max & \left(p_{H} \Delta_{R_{0}}+R^{F}-1\right) I_{00}^{0}-p_{H} \Delta_{B_{00}^{0}}-B_{00}^{0 F}+A & \\
\text { st. } & \Delta_{B_{00}^{0}} \geq \frac{P}{\Delta_{p}} I_{00}^{0} & \left(I C_{00}^{0}\right) \\
& p_{H} \Delta_{B_{00}^{0}}+B_{00}^{0 F} \geq p_{H} \frac{P}{\Delta_{p}} \frac{A}{1-p_{H}\left(\Delta_{R_{0}}-\frac{P}{\Delta_{p}}\right)-R^{F}}+R & \left(P C_{00}^{0}\right)
\end{array}
$$

where the right hand side of $\left(P C_{00}^{0}\right)$ indicates the standard borrower's payoff when she receives the contract $\left(B_{0 j}^{S 0 *}, B_{0 j}^{F 0 *}, I_{0 j}^{0 *}\right)$.

The participation constraint of the standard borrower must be binding. If not the lender can subtract a small and equal amount to $B_{00}^{0 S}$ and $B_{00}^{0 F}$ leaving $\Delta_{B_{00}^{0}}$ unchanged and increasing profits.

By substituting the participation constraint taken with equality into the objective function, the program becomes:

$$
\begin{array}{cc}
\max & \left(p_{H} \Delta_{R}+R^{F}-1\right) I_{00}^{0}+\frac{1-p_{H} \Delta_{R_{0}}-R^{F}}{1-p_{H}\left(\Delta_{R_{0}}-\frac{P}{\Delta_{p}}\right)-R^{F}} A-R \\
\text { st. } & \Delta_{B_{00}^{0}} \geq \frac{P}{\Delta_{p}} I_{00}^{0}
\end{array}
$$


The objective function is thus increasing in $I_{00}^{0}$. Hence also the incentive compatibility constraint has to be binding: $\Delta_{B_{00}^{0}}=\frac{P}{\Delta_{p}} I_{00}^{0}$.

Now, suppose that $B_{00}^{0 F}>0$. Then one can decrease $B_{00}^{0 F}$ and increase $B_{00}^{0 S}$, so that $p_{H} \Delta_{B_{00}^{0}}+B_{00}^{0 F}$ is unchanged. The participation constraint still holds, the expected profit of the lender is unchanged, but now the incentive compatibility is slack: a contradiction. Hence it must be $B_{00}^{O F}=0$. Thus we can study the simplified program:

$$
\begin{array}{cc}
\max & \left(p_{H} \Delta_{R}+R^{F}-1\right) I_{00}^{0}-p_{H} \Delta_{B_{00}^{0}}+A \\
\text { st } & \Delta_{B_{00}^{0}}=\frac{P I_{00}^{0}}{\Delta_{p}} \\
& p_{H} \Delta_{B_{00}^{0}}=p_{H} \frac{P}{\Delta_{p}} \frac{p_{H}\left(\Delta_{R_{0}}-\frac{P}{\Delta_{p}}\right)-R^{F}}{1-p_{0}}+R
\end{array}
$$

from the $(\mathrm{PC})$ :

$$
\Delta_{B_{00}^{0}}(R)=\frac{P}{\Delta_{p}} \frac{A}{1-p_{H}\left(\Delta_{R_{0}}-\frac{P}{\Delta_{p}}\right)-R^{F}}+\frac{R}{p_{H}}
$$

thus substituting in the (IC):

$$
\begin{gathered}
\frac{P}{\Delta_{p}} \frac{A}{1-p_{H}\left(\Delta_{R_{0}}-\frac{P}{\Delta_{p}}\right)-R^{F}}+\frac{R}{p_{H}}=\frac{P I_{00}^{0}}{\Delta_{p}} \\
I_{00}^{0}(R)=\frac{A}{1-p_{H}\left(\Delta_{R_{0}}-\frac{P}{\Delta_{p}}\right)-R^{F}}+\frac{\Delta_{p}}{P p_{H}} R
\end{gathered}
$$

substituting $\Delta_{B_{00}^{0}}(R)$ and $I_{00}^{0}(R)$ into the expected profit of the lender we derive the expected payoff as a function of the cost-minimizing transfer $R$ :

$$
\begin{aligned}
\Pi_{L_{0}}(R) & =\left(p_{H} \Delta_{R_{0}}+R^{F}-1\right)\left(\frac{A}{1-p_{H}\left(\Delta_{R_{0}}-\frac{P}{\Delta_{p}}\right)-R^{F}}+\frac{\Delta_{p}}{P p_{H}} R\right)- \\
& =p_{H}\left(\frac{P}{\Delta_{p}} \frac{A}{1-p_{H}\left(\Delta_{R_{0}}-\frac{P}{\Delta_{p}}\right)-R^{F}}+\frac{R}{p_{H}}\right)+A \\
& =-\frac{\Delta_{p}}{P} \frac{R}{p_{H}}\left(1-p_{H}\left(\Delta_{R_{0}}-\frac{P}{\Delta_{p}}\right)-R^{F}\right)
\end{aligned}
$$

thus $\Pi_{L_{0}}(R)<0$ if $R>0$ and $\Pi_{L_{0}}(R)=0$ if $R=0$.

Second step. The commercial bank makes negative profits when offering the transfer $R$ to the standard borrower. Thus, the amount $R$ can be paid to standard borrowers only if commercial banks receive it from ethical banks. In turn this is possible only if the ethical bank makes positive profits on motivated borrowers. Thus, we must verify whether a cross-subsidy between banks is 
feasible. This can be checked by solving the following program.

$$
\begin{array}{cc}
\max _{\Delta_{B_{11}^{1}}, B_{11}^{F 1}, I_{11}^{1}, R} & p_{H} \Delta_{B_{11}^{1}}+B_{11}^{F 1}+p_{H} \Delta_{\theta}+\theta-A \\
\text { s.t. } & \Delta_{B_{11}^{1}}+\Delta_{\theta} \geq \frac{P I_{11}^{1}}{\Delta_{p}} \\
& \left(\left(p_{H} \Delta_{R_{1}}+R^{F}-1\right) I_{11}^{1}-p_{H} \Delta_{B_{11}^{1}}-B_{11}^{F 1}+A\right) q \\
& -\frac{\Delta_{p}}{P} \frac{R}{p_{H}}\left(1-p_{H}\left(\Delta_{R_{0}}-\frac{P}{\Delta_{p}}\right)-R^{F}\right)(1-q) \geq 0 \\
& p_{H} B_{0 j}^{S 0 *}+R \geq p_{L} \Delta_{B_{11}^{1}}+B_{11}^{F 1}+P I_{11}^{1}
\end{array}
$$

where $\left(I R_{11}^{L 1}\right)$ imposes that the cross subsidy $R$ between the $q$ ethical banks and the $1-q$ standard banks is feasible. Note that expected profits $\Pi_{L_{0}}(R)$ just derived before appears in the constraint.

We know that the solution when $R=0$ and derived in Lemma 1 lies in the intersection between $\left(I R_{11}^{L 1}\right)$ and $\left(S S_{1}^{B 1}\right)$ and corresponds to a debt contract $\left(B_{11}^{F 1 *}=0\right)$. Totally differentiating the previous two constraints we obtain:

$$
\begin{gathered}
{\left[\begin{array}{cc}
-\left(p_{H} \Delta_{R_{1}}+R^{F}-1\right) & p_{H} \\
-P & -p_{L}
\end{array}\right] d\left[\begin{array}{c}
I_{11}^{1} \\
\Delta_{B_{11}^{1}}^{1}
\end{array}\right]=} \\
{\left[\begin{array}{c}
-\frac{\Delta_{p}}{P p_{H}}\left(1-p_{H}\left(\Delta_{R_{0}}-\frac{P}{\Delta_{p}}\right)-R^{F}\right) \frac{(1-q)}{q} \\
-1
\end{array}\right] d R}
\end{gathered}
$$

Hence:

$$
\frac{d \Delta_{B_{11}^{1}}}{d R}=\frac{p_{H}\left(p_{H} \Delta_{R_{1}}+R^{F}-1\right) q-\left(p_{H}-p_{L}\right)\left(1-p_{H}\left(\Delta_{R_{0}}-\frac{P}{\left(p_{H}-p_{L}\right)}\right)-R^{F}\right)(1-q)}{p_{H}\left(P p_{H}+\left(R^{F}+p_{H} \Delta_{R_{1}}-1\right) p_{L}\right) q}
$$

Therefore $\frac{d \Delta_{B_{11}^{1}}}{d R}<0$ iff:

$$
q<\frac{1}{\frac{p_{H}\left(p_{H} \Delta_{R_{1}}+R^{F}-1\right)}{\left(p_{H}-p_{L}\right)\left(1-p_{H}\left(\Delta_{R_{0}}-\frac{P}{\left(p_{H}-p_{L}\right)}\right)-R^{F}\right)}+1}=\bar{q}
$$

and since one can check that:

$$
\begin{gathered}
\left(p_{H}-p_{L}\right)\left(1-p_{H}\left(\Delta_{R_{0}}-\frac{P}{\left(p_{H}-p_{L}\right)}\right)-R^{F}\right)> \\
p_{H}\left(p_{H} \Delta_{R_{1}}+R^{F}-1\right)
\end{gathered}
$$

it must be: $\bar{q}>\frac{1}{2}$. Thus, $q<\frac{1}{2}$ is a sufficient condition for $\frac{d \Delta_{B_{11}^{1}}}{d R}<0$. The previous inequality means that, as $R$ increases, $B_{11}^{S 1}-B_{11}^{F 1}$ decreases. As a consequence, if $B_{11}^{F 1}=0$, we can conclude that the candidate equilibrium contract with cross-subsidy is not welfare improving.

The three constraints can be rewritten as:

$$
\begin{array}{cc}
I_{11}^{1} \leq \frac{\Delta_{p}}{P} \Delta_{B_{11}^{1}}+\frac{\Delta_{p}}{P} \Delta_{\theta} & \left(I C_{11}^{B 1}\right) \\
I_{11}^{1} \geq \frac{p_{H} \Delta_{B_{11}^{1}}-A}{p_{H} \Delta_{R_{1}}+R^{F}-1}+\frac{\Delta_{p}}{P} \frac{R}{p_{H}} \frac{1-p_{H}\left(\Delta_{R_{0}}-\frac{P}{\Delta_{p}}\right)-R^{F}}{p_{H} \Delta_{R_{1}}+R^{F}-1} \frac{(1-q)}{q} & \left(I R_{11}^{L 1}\right) \\
I_{11}^{1} \leq \frac{p_{H}}{P} B_{0 j}^{S 0 *}-\frac{p_{L}}{P} \Delta_{B_{11}^{1}}^{1}+\frac{R}{P} & \left(S S_{1}^{B 1}\right)
\end{array}
$$


Notice that as $R$ increases, the $(S S)$ line in Figure 3 moves up, while line $(I R)$ moves left. $\left(I C_{11}^{B 1}\right)$ instead does not move. Hence, the equilibrium could lie on the intersection between $\left(I C_{11}^{B 1}\right)$ and $\left(I R_{11}^{L 1}\right)$, for $R$ quite big. However from that point on it would still be true that $\frac{d \Delta_{B_{11}^{1}}}{d R}<0$, because $\left(I C_{11}^{B 1}\right)$ is unchanged and $\left(I R_{11}^{L 1}\right)$ moves left.

It still remains to be verified whether, in the optimal contract with crosssubsidy, $B_{11}^{F 1}=0$. One can check that if the optimal contract is in the intersection between $\left(I R_{11}^{L 1}\right)$ and $\left(S S_{1}^{B 1}\right)$ the $\frac{\partial \Delta_{B_{11}^{1}}}{\partial B_{11}^{F 1}}$ is identical to $(27)$ and negative. Therefore an increase in $B_{11}^{F 1}$ lowers welfare. If the optimal contract is instead in the intersection between $\left(I C_{11}^{B 1}\right)$ and $\left(I R_{11}^{L 1}\right)$, it is easy to check that an increase in $B_{11}^{F 1}$ would leave the line $\left(I C_{11}^{B 1}\right)$ unchanged in Figure 3, but move the line $\left(I R_{11}^{L 1}\right)$ to the left, and cause a decrease in welfare. 


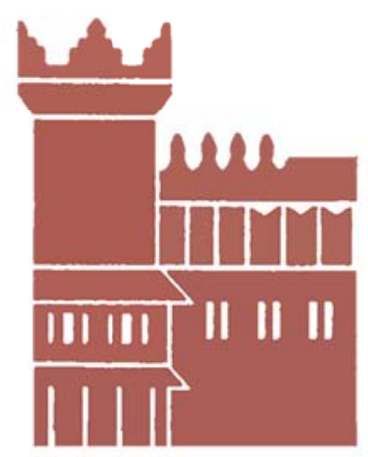

Alma Mater Studiorum - Università di Bologna DEPARTMENT OF ECONOMICS

Strada Maggiore 45

40125 Bologna - Italy

Tel. +39051 2092604

Fax +390512092664

http://www.dse.unibo.it 